
FACULDADE DE CIÊNCIAS DA EDUCAÇÃO E DA SAÚDE FACES

PROGRAMA DE INICIAÇÃO CIENTÍFICA

REGIO ARAUJO DA COSTA

EVOLUÇÃO DE ROTAS E DINÂMICAS MIGRATÓRIAS EM TIRANÍDEOS NEOTROPICAIS 


\title{
Unce $=\mathrm{B}$ \\ Centro Unıversıtáno de Brasilıa
}

\section{REGIO ARAUJO DA COSTA}

\section{EVOLUÇÃO DE ROTAS E DINÂMICAS MIGRATÓRIAS EM TIRANÍDEOS NEOTROPICAIS}

\author{
Relatório final de pesquisa de Iniciação \\ Científica apresentado à Assessoria de \\ Pós-Graduação e Pesquisa pela \\ Faculdade de Ciências da Educação e da \\ Saúde - FACES.
}

Orientação: Dr. Raphael Igor da Silva Corrêa Dias

\section{BRASÍLIA-DF \\ 2016}




\title{
EVOLUÇÃO DE ROTAS E DINÂMICAS MIGRATÓRIAS EM TIRANÍDEOS NEOTROPICAIS
}

\author{
Regio Araujo da Costa - UniCEUB, PIC voluntário \\ regioadc@gmail.com \\ Dr. Raphael Igor da Silva Corrêa Dias - UniCEUB, professor orientador \\ raphael.dias@uniceub.br
}

Migração é um fenômeno biológico caracterizado pelo deslocamento espacial de indivíduos entre locais diferentes com retorno posterior ao lugar de origem. Esse fenômeno é observado em vários grupos de animais, porém, é mais comumente encontrado em aves, onde o mesmo apresenta enormes variações devido a fatores físicos e ecológicos. A migração ocorre de forma regular, sendo uma alternativa de sobrevivência de muitas espécies devido a sazonalidade de recursos e fenômenos naturais. A região Neotropical apresenta uma elevada diversidade de aves e faz parte da rota de muitas espécies migratórias. Entretanto, poucas informações sobre rotas migratórias e locais de invernada estão disponíveis para a maior das espécies migrantes de Passeriformes brasileiros. A família Tyrannidae é um dos táxons mais representativos e numerosos de aves do mundo, sua distribuição é exclusiva do continente americano e sua ocupação compreende os mais variados ambientes. Nesse sentido, o objetivo do presente estudo foi investigar os padrões de deslocamento de espécies consideradas migratórias segundo a literatura. Para tanto, foram selecionadas quatro espécies de tiranídeos: Chibum (Elaenia chiriquensis), Irré (Myiarchus swainsoni), Maria-ferrugem (Casionrnis rufus) e Suiriri-cavaleiro (Machetornis rixosa). Foram utilizados dados secundários disponíveis nas bases Xeno-canto e WikiAves. De cada base foram extraídas informações referentes à localização espacial (latitude e longitude), observações comportamentais, além de informações temporais relacionadas aos registros (data da observação). As análises envolveram comparações temporais das distribuições dos pontos no programa RStudio. Os resultados indicaram pequenos deslocamentos latitudinais ao longo do ano para todas as espécies investigadas. Adicionalmente, não foi observado uma orientação consistente nos deslocamentos feitos para todas as espécies estudadas. Os resultados parecem sugerir que o processo migratório nas espécies investigadas ocorre em uma escala menor, possivelmente relacionado a variações nas condições ambientais locais.

Palavras-chave: Aves. Migração. Sazonalidade. Tyrannidae. 
Sumário

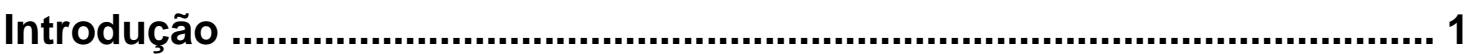

Matérias e Métodos .................................................................................. 5

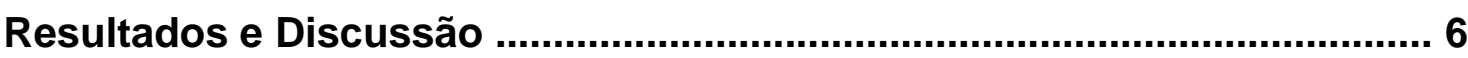

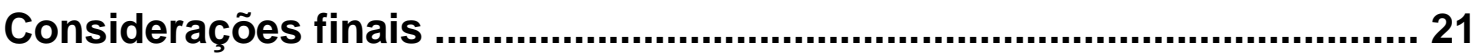

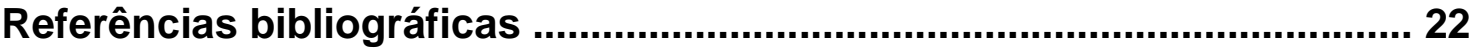

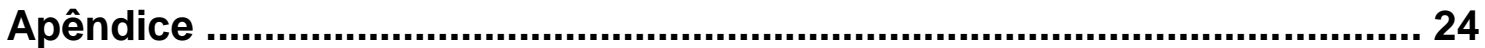




\section{Introdução}

O termo migração é uma palavra derivada do latim migrare, que significa a capacidade de um indivíduo de mover-se de um local para o outro em um espaço e depois retornar ao lugar de onde partiu (Åkesson e Hedenström, 2004).

No sentido estrito, migração significa o deslocamento realizado anualmente por uma determinada população animal e que se repete de forma estacional. Em uma determinada época do ano, esses animais se deslocam de sua área de reprodução para áreas de alimentação e descanso, depois retornam a sua área de reprodução original (Alerstam e Hedenström, 1998).

A migração ocorre em quase todos os grupos de seres vivos, desde uma simples bactéria até os seres humanos (Berthold, 2001). Por exemplo, nos invertebrados, crustáceos marinhos podem migrar por vários quilômetros no fundo do mar e enxames de gafanhotos invadem sazonalmente grande parte dos continentes (Baker, 1991). Nos vertebrados, salamandras e sapos migram vários quilômetros para as áreas de desova e as tartarugas marinhas migram cerca de $3.000 \mathrm{~km}$ para chegar ao litoral e colocar seus ovos (Baker, 1991). Entre os mamíferos esse fenômeno é observado em baleias e focas, que podem chegar a distancias de $20.000 \mathrm{~km}$ (Baker, 1991). Nesse sentido, a migração pode englobar percursos pequenos, de algumas centenas de metros, até percursos longos, composto por milhares de quilômetros (Milner-Gulland et al, 2011). Embora a migração seja evidente em todos esses grupos animais, nas aves ela é mais desenvolvida e ampla (Newton, 2008). Porém, nem todas as aves migram, muitas permanecem em uma região ou local durante o ano todo, sendo denominadas residentes (Sick, 1993). A migração das aves difere do voo comum do dia-a-dia pela maior duração da viagem e maior altitude em que a mesma geralmente ocorre (Newton, 2008).

As aves migram por dois fatores principais: endógenos, regulado pela hipófise, que controla boa parte do sistema endócrino e as gônadas, que se desenvolvem antes da reprodução, estimulando as aves a voltarem para suas áreas de partida, pela falta de atividade das mesmas; e exógenos, que são caracterizados por fatores como a duração do dia, luminosidade, fatores tróficos e meteorológicos (Andrade, 1993). 
A migração das aves pode se estender por distâncias de mais de $10.000 \mathrm{~km}$ (Newton, 2008). Geralmente as migrações são realizadas em alturas abaixo dos $600 \mathrm{~m}$, porém, em regiões inóspitas como mares e desertos, a altura varia de 2000 a 3000 metros. Durante a noite, certas marrecas podem chegar a 9.000 metros de altura (Andrade, 1993).

Essas longas migrações não exigem apenas habilidades extraordinárias de navegação, mas reservas corporais maciças para abastecer os voos e o esforço interrupto durante todo o percurso da migração (Newton, 2008). As aves acumulam muita gordura, necessária para a resistência física durante as migrações, as que realizam migrações mais longas chegam a ficar com o dobro do peso normal. Essa gordura é acumulada em todo o corpo, exceto no coração (Andrade, 1993), todos esses fatores resultam em uma elevada taxa de mortalidade (Newton, 2008).

Existem dois níveis básicos de orientação das aves: migração apoiada em caracteres fito-fisionômicos (como matas e savanas), caracteres topográficos (como costas marinhas, desertos, lagos, mar, montanhas, rios, beira de rios) e fatores meteorológicos (como correntezas de ar em ascensão e ventos) e migrações que são guiadas por sentidos, como uma bússola, ignorando a superfície da Terra (Andrade, 1993).

As migrações sazonais são divididas em: 1) migração altitudinal, que é a migração com variação na altitude, sendo comum em regiões montanhosas onde as aves sobem e descem a procura de alimento (e.g algumas espécies de beija-flores); 2) migração longitudinal, em que há variações de longitude entre leste e oeste ou vice-versa e acompanha as frentes isotérmicas; 3) migração latitudinal, que ocorre entre diferentes latitudes, geralmente da região norte a região sul no outono e regressando na próxima primavera; e 4) migração por radiação, que é caracterizada pela dispersão ou movimentos realizados para várias direções, ou seja, indivíduos da mesma espécie migram para regiões diferentes (Negret, 1981).

Os sistemas migratórios descritos para as América do Sul e do Norte são os: Temperado-Tropical ou Neártico-Neotropical (para indicar as espécies que migram entre as latitudes temperadas e tropicais) e o Frio-Temperado (para indicar as espécies que migram entre as latitudes temperadas) (Joseph, 1997; Cueto e Jahn, 2008). Migrante neotropical, segundo Hayes (1995), é a 
espécie que se reproduz na América do Sul e migra regularmente para o hemisfério norte durante a estação não reprodutiva. Porém, Cueto e Jahn (2008) propuseram o uso do termo "migrantes austrais neotropicais" para as aves que migram latitudinalmente dentro da América do Sul, em razão da região biogeográfica onde as aves se encontram (Cueto e Jahn, 2008). Essa denominação abrange as espécies que se reproduzem no Sul da América do Sul (principalmente Argentina, sul do Brasil, Chile, Paraguai e Uruguai) e passam a época não reprodutiva no trópico da América do Sul (e.g., Bolívia, Brasil, Colômbia, Equador, Peru e Venezuela), que constituem o sistema migratório Temperado-Tropical da América do Sul (Joseph, 1997; Cueto e Jahn, 2008).

A região Neotropical é a região biogeográfica que abrange parte do Sul da América do Norte, região que compreende o México, América Central e América do Sul (Amorim e Pires, 1996). Essa região possui alta biodiversidade e variadas características climáticas e fisiográficas (Goldani e Carvalho, 2003), possui mais de $30 \%$ de toda a diversidade de aves no mundo (Ridgely e Tudor, 1989, 1994). Entretanto, essa região tem sido pouco estudada (Martin, 2004). O Brasil ocupa uma considerável parte da região Neotropical e a avifauna dessa região possui numerosas espécies endêmicas que nela evoluíram (Sick, 1997). De acordo com a escassa literatura, a maioria dos migrantes Neotropicais realizam migrações de média e curta distância dentro da América do Sul (Chesser, 1994). Dessa maneira, as migrações altitudinais que ocorrem na América do sul constituem um padrão raro de migração em escala regional (Areta e Bodrati, 2010).

Tyrannidae é uma das maiores e mais diversificadas famílias de aves, com cerca de 400 espécies e 100 gêneros (Fitzpatrick, 1980), sua distribuição é restrita ao continente americano (Fitzpatrick, 2004) e tem maior número de espécies no Brasil (Sick, 1997).

O Brasil é o segundo país com maior diversidade de aves, possui 1.901 espécies de aves documentadas (CBRO, 2014), e faz parte da rota de muitas espécies migratórias (ICMBio, 2014). Durante a rota migratória das aves, diversos habitats são selecionados devido a disponibilidade de recursos, hábitos alimentares e táticas de forrageamento das espécies envolvidas. Porém, devido a distribuição não-contínua desses recursos, as espécies 
migrantes se concentram em áreas específicas para se alimentarem, realizarem a muda e adquirirem reservas energéticas para a continuação de longas viagens. Portanto, esses locais de concentração das aves têm importância fundamental para sua conservação (ICMBio, 2014).

No Brasil, destacam-se as migrações do inverno do Norte (inverno boreal) e do inverno do Sul (inverno austral) (Antas, 1994; Sick, 1997; Cabral et al., 2006; Campos et al., 2008). Os migrantes vêm ao Brasil em busca de locais de invernada, encontram alimentação farta para dar continuidade ao seu ciclo de vida (Telino Jr. et al., 2003). Centenas de indivíduos que invernam no extremo Norte utilizam essas áreas para pouso e alimentação logo após o período reprodutivo, que acontece em maio e julho (Sick, 1997; Cabral et al., 2006).

A destruição, fragmentação e degradação ambiental tendem a ameaçar espécies migratórias de forma acentuada (Peterson, 1971), o que reforça a necessidade de se compreender a dinâmica migratória das espécies. Além disso, os padrões migratórios atuais demonstram evidências de que estão sendo alterados pelo aquecimento global (Crick, 2004; Niven et al., 2004; Pulido e Berthold, 2010). Mudanças já foram identificadas como o adiantamento dos períodos reprodutivos (Dunn, 2004), datas de partida e chegada (Cotton, 2003), diminuição da atividade migratória por causa do hábito residente (Pulido e Berthold, 2010), mudanças na latitude nas áreas de invernada (Fiedler et al., 2004; Niven et al., 2004) e de reprodução (Brommer, 2004).

Apesar das publicações recentes no Brasil sobre migração em aves, ainda existem várias lacunas de conhecimento sobre as rotas migratórias dentro do país (ICMBio, 2014). Uma possível explicação para a carência de estudos sobre esses migrantes pode estar associada a seus movimentos complexos, que incluem deslocamentos altitudinais, latitudinais e longitudinais; podendo ser movimentos regionais ou locais, em decorrência da disponibilidade de recursos. Portanto, para estudos dos seus movimentos deve-se considerar não apenas a escala espacial, mas também a temporal (Alves, 2007).

Neste trabalho foram investigados os padrões migratórios de quatro espécies de tiranídeos Chibum (Elaenia chiriquensis), Irré (Myiarchus 
swainsoni), Maria-ferrugem (Casiornis rufus) e Suiriri-cavaleiro (Machetornis rixosa), com o objetivo de apresentar informações sobre movimentações sazonais e avaliar se o deslocamento está associado a fatores reprodutivos e estacionais, podendo assim, fornecer informações para elaboração de planos de conservação.

\section{Materiais e métodos}

\subsection{Coleta de dados e espécies estudadas}

Os dados utilizados nessa pesquisa foram obtidos a partir de registros de imagens e cantos disponibilizados, respectivamente, nos sites WikiAves (http://www.wikiaves.com.br/) e Xeno-canto (www.xeno-canto.org). As aves selecionadas para esses estudos foram quatro espécies de tiranídeos da família Tyrannidae descritos como migrantes por Sick (1997): Chibum (Elaenia chiriquensis), Irré (Myiarchus swainsoni), Maria-ferrugem (Casiornis rufus) e Suiriri-cavaleiro (Machetornis rixosa). Foi feita uma busca das espécies selecionadas nos meses de janeiro a março de 2016 e todas as informações disponíveis sobre essas aves foram registradas, como data e hora que o registro foi feito, local de observação (município) e observações importantes (e.g. atividades reprodutivas, forrageamento, etc).

\section{$2.2 \quad$ Análises dos dados}

Os padrões de distribuição geoespacial foram analisados no Programa RStudio com o uso dos pacotes maps, rgdal, geosphere e gsubfn.

Os centroides das localidades que não tinham informação de latitude e longitude foram identificados a partir do arquivo shapefile dos municípios brasileiros disponível no site do IBGE, utilizando o pacote geosphere. Foi utilizado um algoritmo para remover os outliers que estejam uma vez e meia a distância interquartílica como uma forma de diminuir a influência de valores extremos na interpretação dos dados. Foi comparado o deslocamento (em km) do centroide dos pontos por mês em relação ao centroide do conjunto de todos os pontos. Foi também calculada a distância em relação ao centroide dos 
pontos do mês anterior (ex. foi calculada a distância dos pontos de fevereiro com os de janeiro). Adicionalmente, foi calcula a envoltória convexa (convex Hull) dos conjuntos de pontos separados por mês e foi avaliada a sobreposição entre os polígonos que representam os meses. Foi avaliada a orientação dos deslocamentos dos polígonos. Para essa avaliação foram utilizados apenas os anos de 2009 até 2015 devido a maior disponibilidade de dados.

\section{Resultados e discussão}

Os resultam indicam que a abundância da espécie Machetornis rixosa (suiriri-cavaleiro) durante o período entre 2009 e 2015 foi constante, apresentando pouca variação na quantidade de espécies durante todo o ano, mantendo uma quantidade de 400 a 600 indivíduos em todos os meses (Figura 1). Porém, houve um leve declínio do mês de fevereiro a abril, ficando em torno de 400 a 450, indivíduos e novamente estabilizando a partir de maio. Houve também pouca variação nos locais de concentração da espécie, sendo encontrado predominantemente nas regiões Centro-Oeste, Sudeste e Sul, e em pequenas quantidades em alguns países da América do Sul, como Argentina e Paraguai (Figura 2). A migração latitudinal e longitudinal apresentou deslocamento em todos os sentidos, somente nos meses de setembro a outubro, durante a primavera, houve deslocamento somente em direção sul (Figura 3, (j)), possivelmente devido à abundância de alimentos nesta estação do ano.

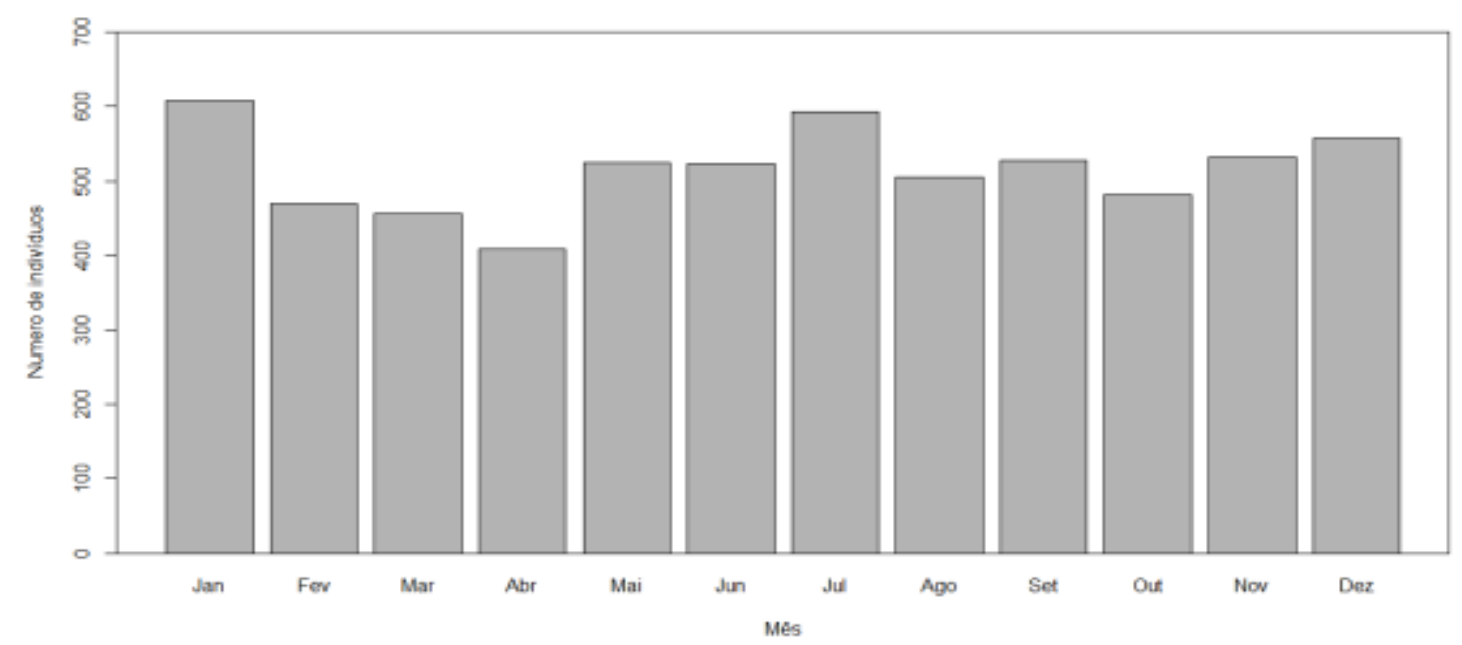

Figura 1: Abundância média mensal da população de Machertonis rixosa (suiriri-cavaleiro) durante o período de 2009 a 2015. 


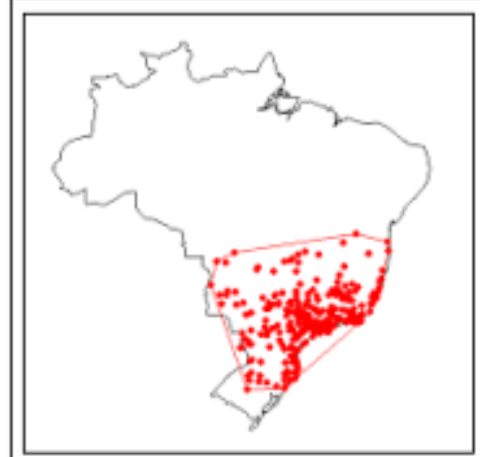

(a)

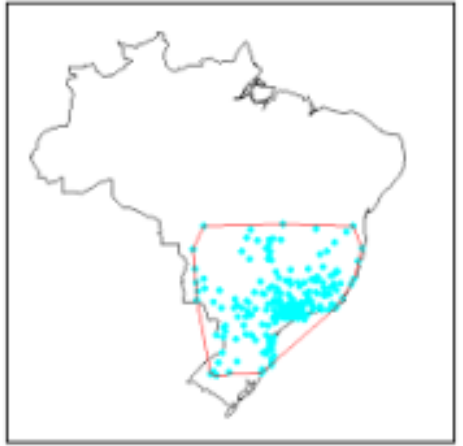

(d)

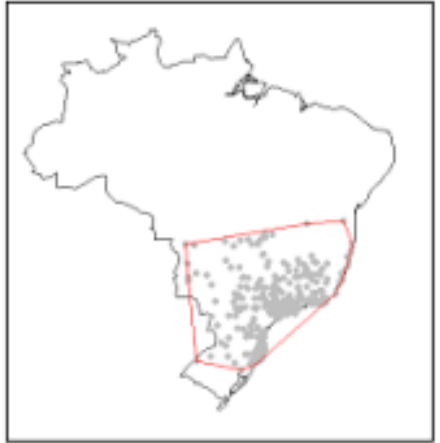

(g)

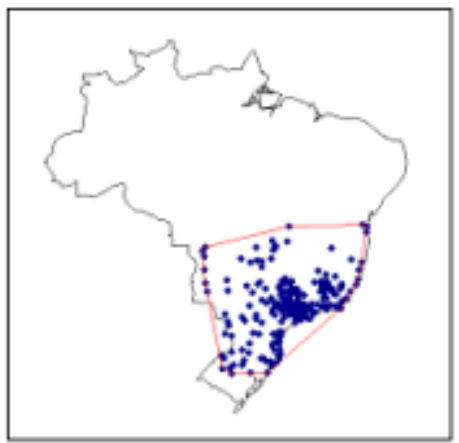

(j)

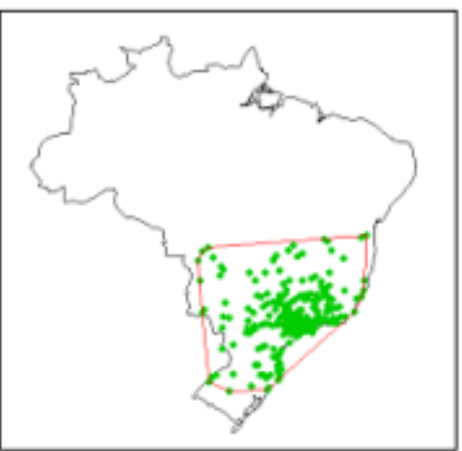

(b)

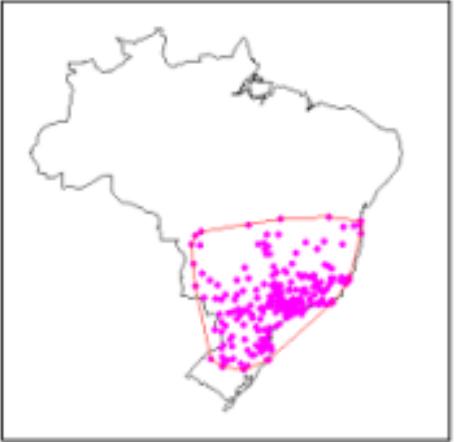

(e)

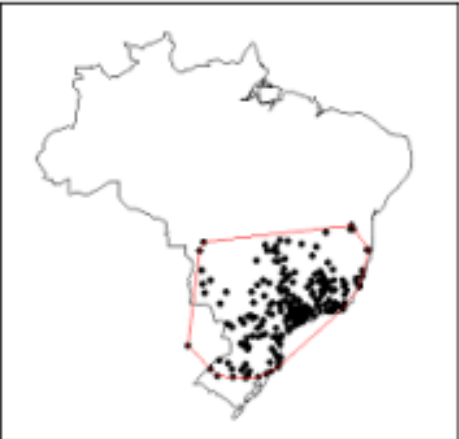

(h)

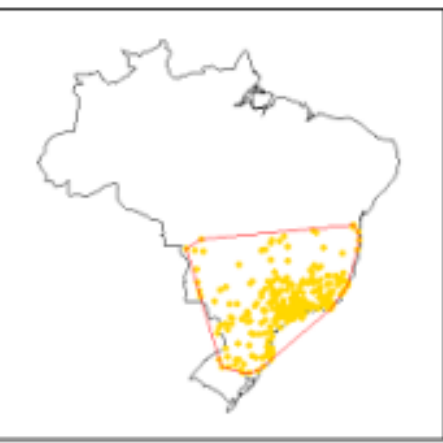

(k)

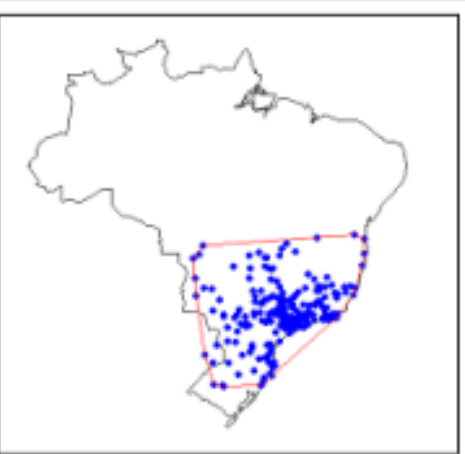

(c)

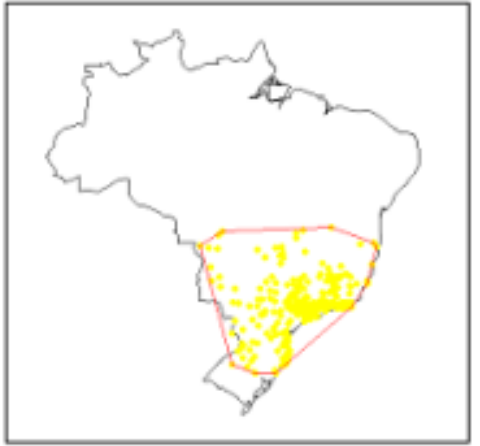

(f)

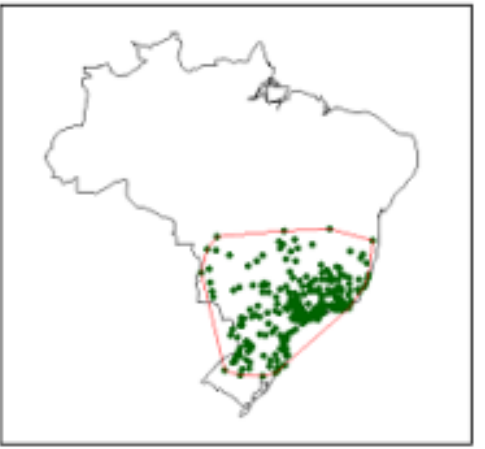

(i)

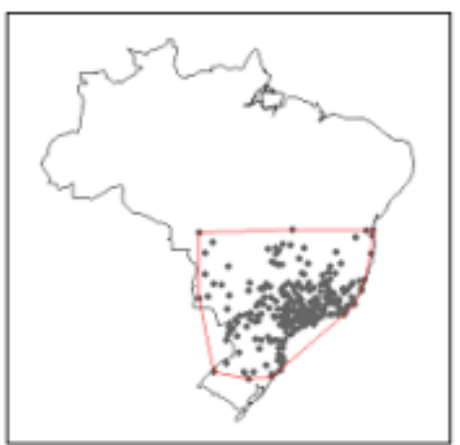

(I)

Figura 2: Concentração média mensal da população de Machetornis rixosa (suiriri-cavaleiro) durante o período de 2009 a 2015. a) Janeiro; b) Fevereiro; c) Março; d) Abril; e) Maio; f) Junho; g) Julho; h) Agosto; i) Setembro; j) Outubro; k) Novembro; I) Dezembro. 


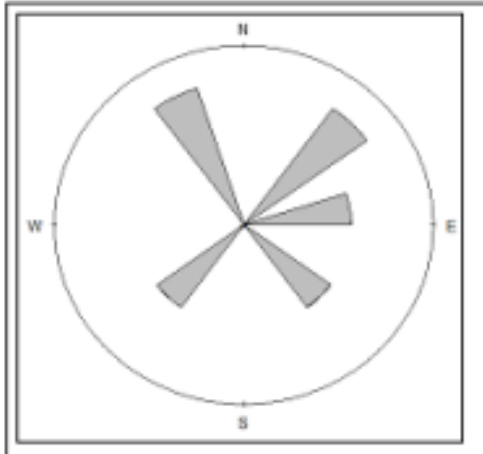

(a)

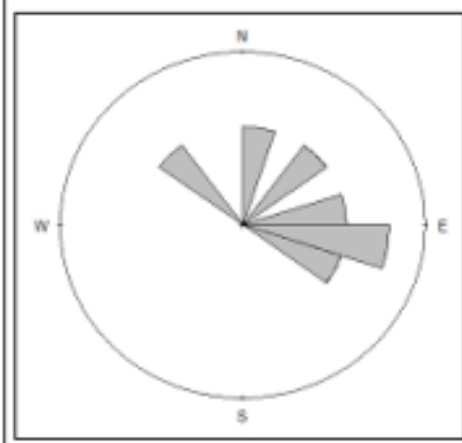

(d)

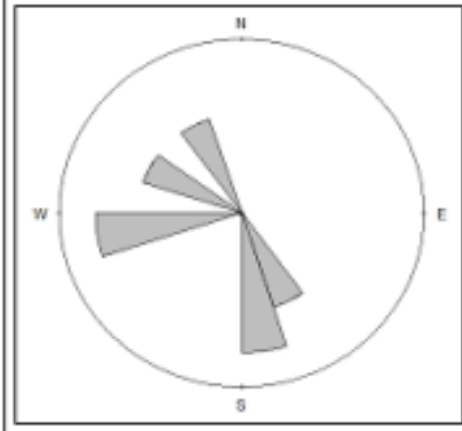

(g)

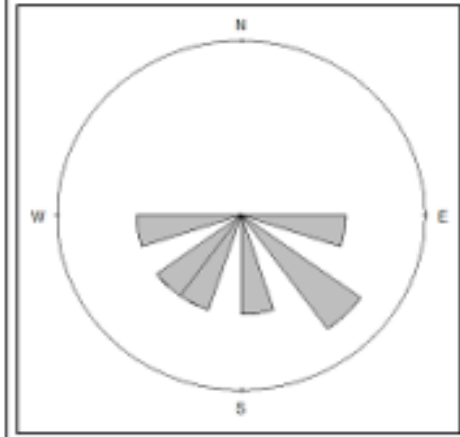

(j)

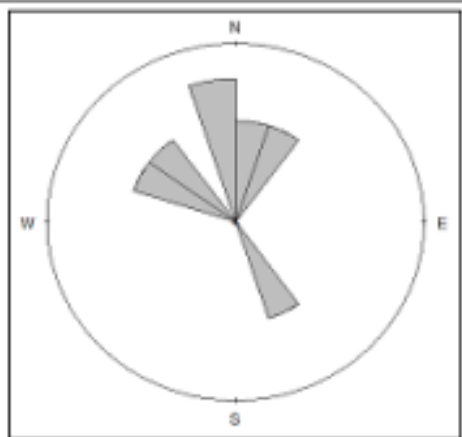

(b)

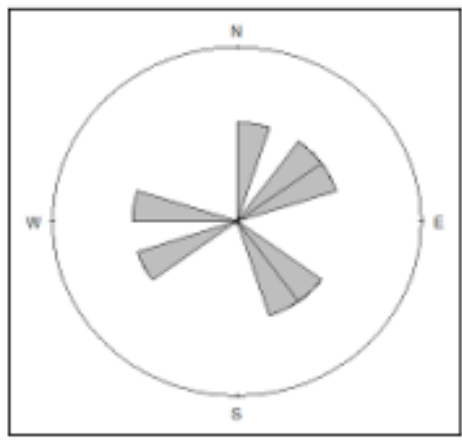

(e)

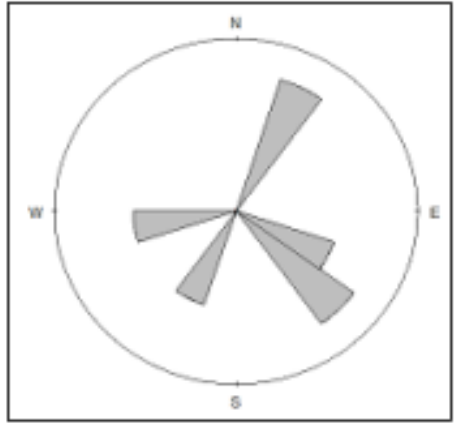

(h)

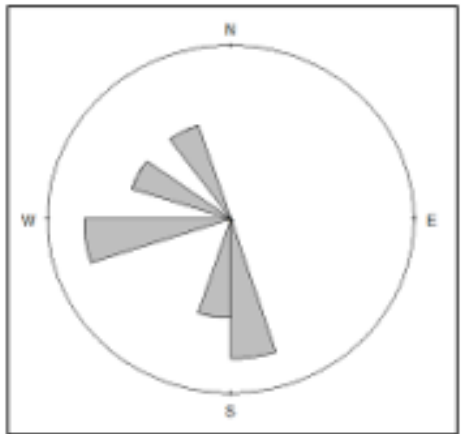

(k)

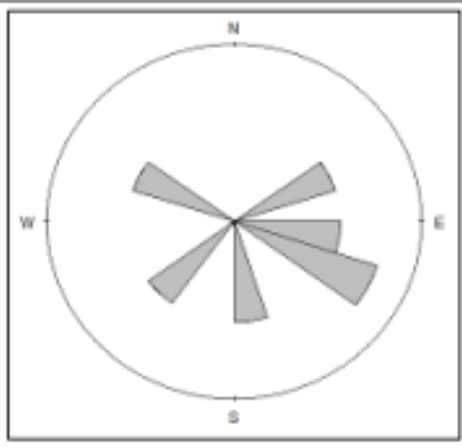

(c)

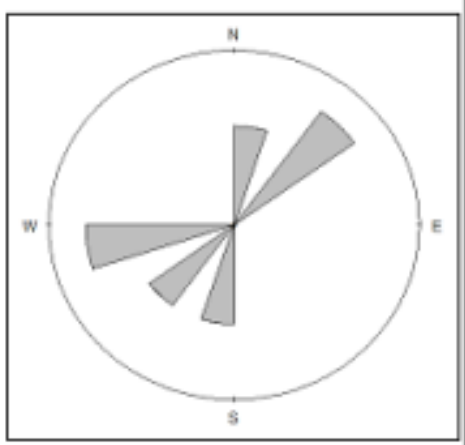

(f)

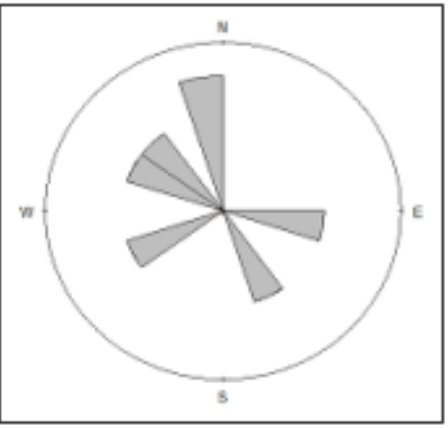

(i)

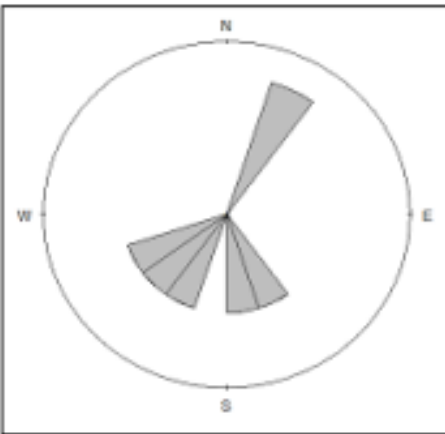

(I)

Figura 3: Variação em relação ao mês anterior na orientação do deslocamento da população de Machetornis rixosa (suiriri-cavaleiro) durante o período de 2009 a 2015. a) JaneiroDezembro; b) Fevereiro-Janeiro; c) Março-Fevereiro; d) Abril-Maio; e) Maio-Abril; f) JunhoMaio; g) Julho-Junho; h) Agosto-Julho; i) Setembro-Agosto; j) Outubro-Setembro; k) NovembroOutubro; I) Dezembro-Novembro. 
A espécie Casiornis rufus (maria-ferrugem) apresentou pouca variação na abundância de indivíduos nos meses de novembro a junho, estações verão e outono, sendo observados entre 40 a 70 indivíduos, havendo um crescimento em julho, agosto e um pico em setembro, estação que corresponde ao inverno Neotropical, apresentando em torno de 100 a 150 indivíduos, possivelmente devido a sazonalidade que ocorre na região central do Brasil. $O$ aumento no número de indivíduos pode estar relacionado ao incremento na disponibilidade de um recurso importante para a espécie e a diminuição da competição com outras espécies que tendem a deixar a região durante esse período. A densidade volta a declinar no final de outubro (Figura 4). Houve também pouca variação nos locais de concentração da espécie, sendo encontrado predominantemente nas regiões Centro-Oeste, Sudeste e Sul e algumas espécies no Peru (Figura 5). A migração latitudinal e longitudinal apresentou deslocamento em todos os sentidos, somente nos meses de setembro a outubro, durante a primavera, houve deslocamento somente em direção oeste (Figura 6, (j)), podendo ser característica de migração devido a sazonalidade de recursos dessa estação do ano em regiões do Centro-Oeste.

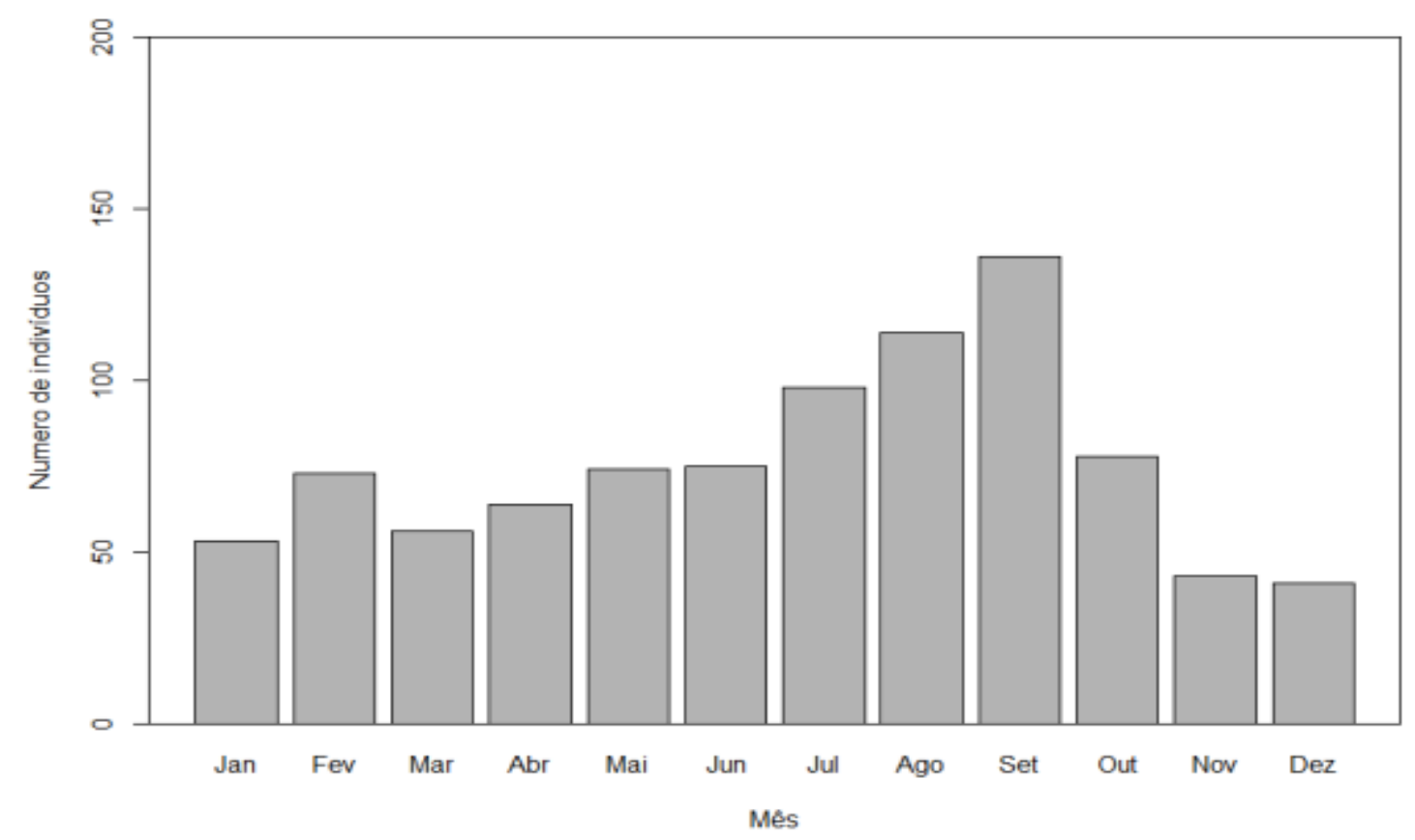

Figura 4: Abundância média mensal da população de Casiornis rufus (maria-ferrugem) durante o período de 2009 a 2015. 


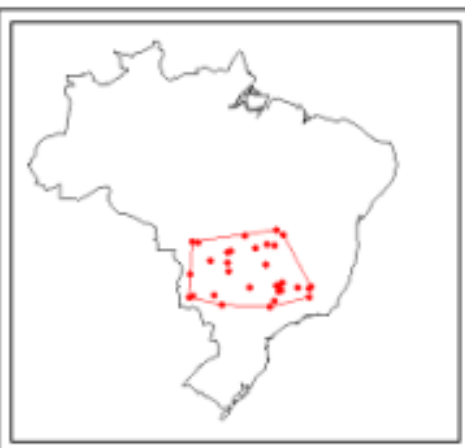

(a)

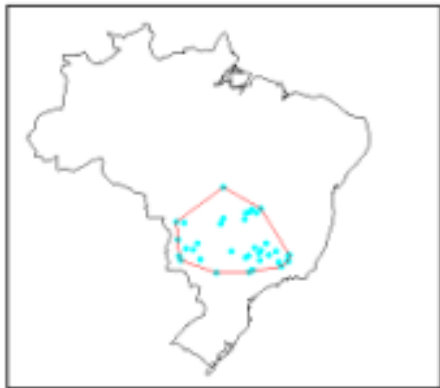

(d)

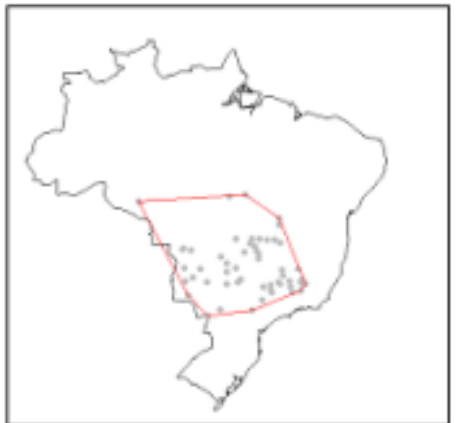

(g)

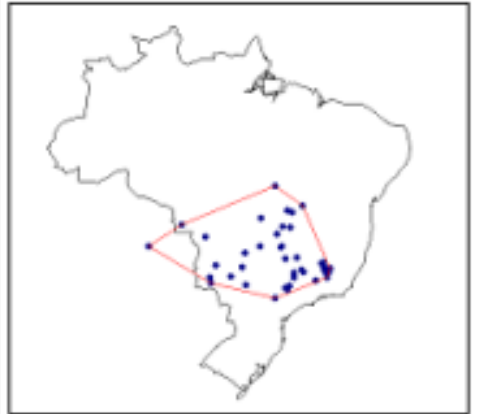

(j)

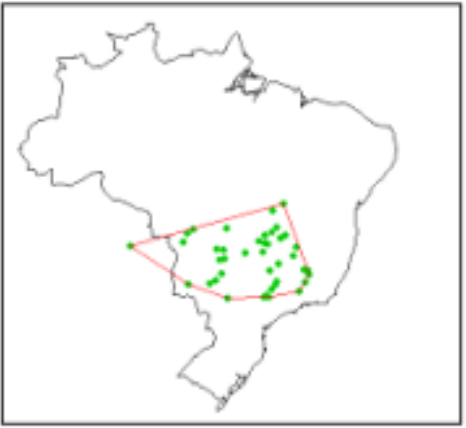

(b)

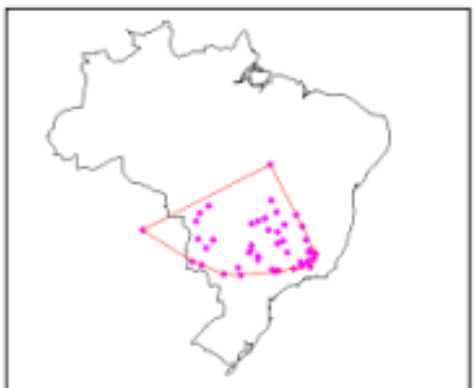

(e)

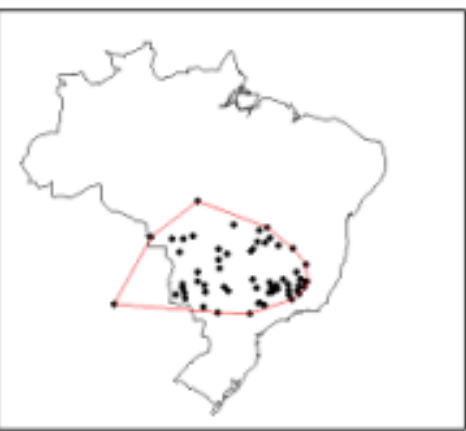

(h)

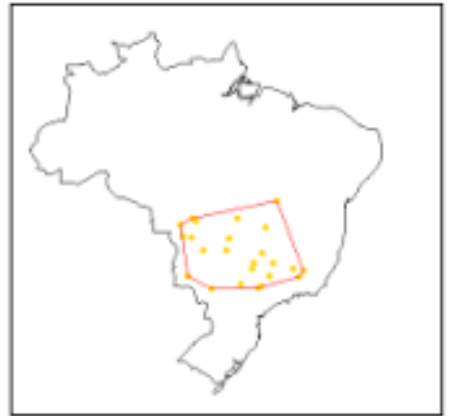

(k)

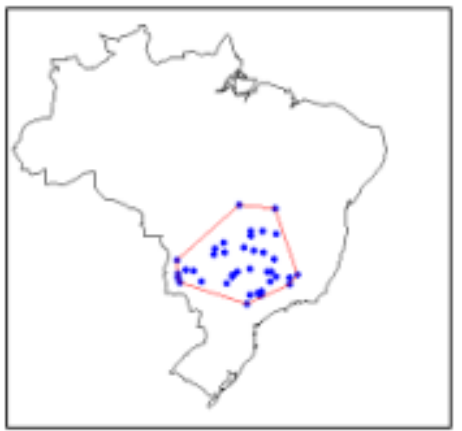

(c)

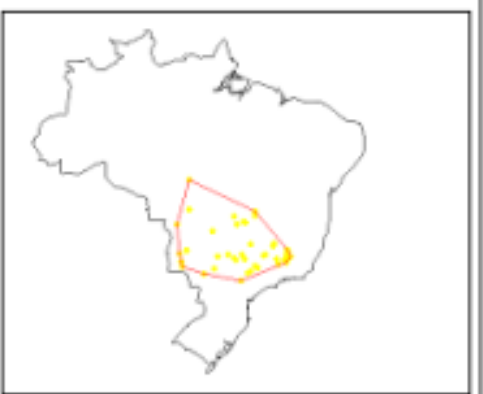

(f)

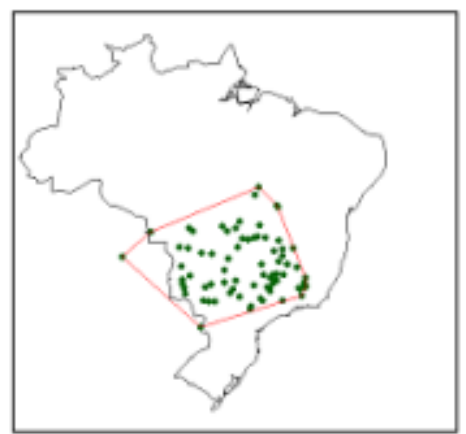

(i)

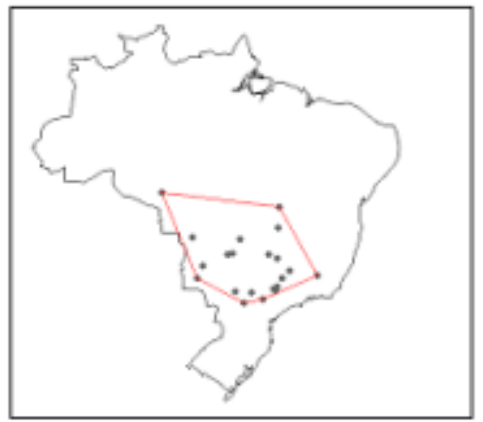

(I)

Figura 5: Concentração média mensal da população de Casiornis rufus (maria-ferrugem) durante o período de 2009 a 2015. a) Janeiro; b) Fevereiro; c) Março; d) Abril; e) Maio; f) Junho; g) Julho; h) Agosto; i) Setembro; j) Outubro; k) Novembro; I) Dezembro. 


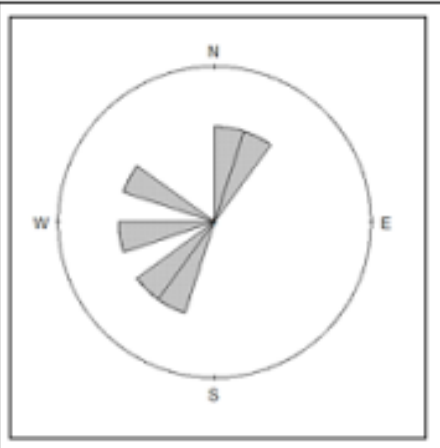

(a)

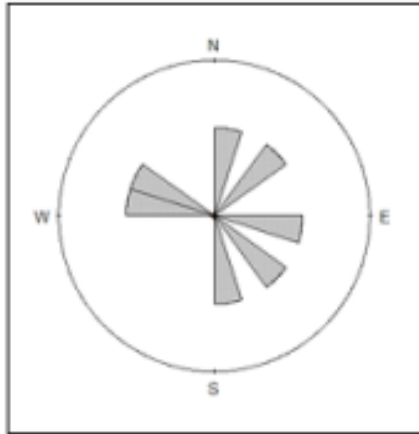

(d)

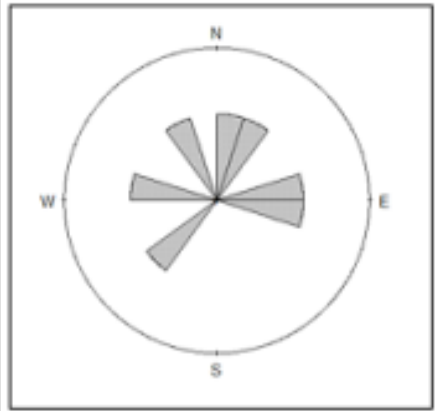

(g)

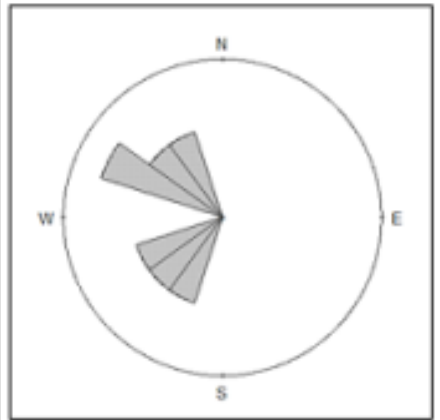

(j)

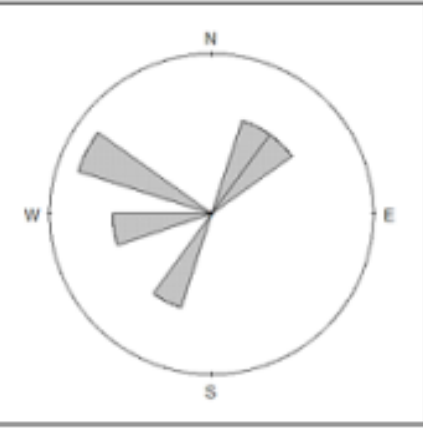

(b)

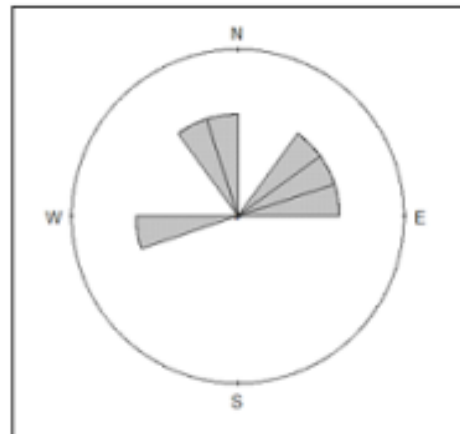

(e)

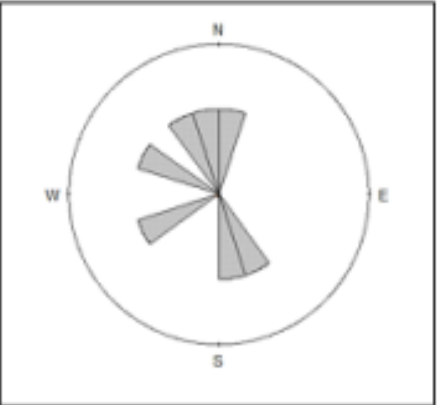

(h)

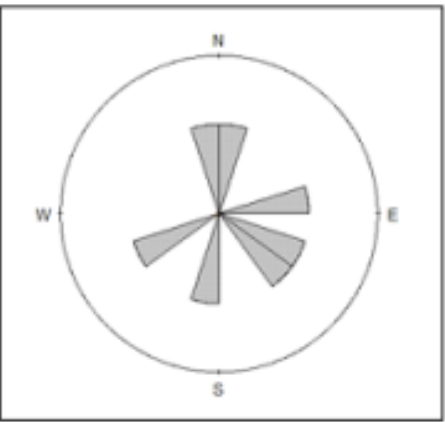

(k)

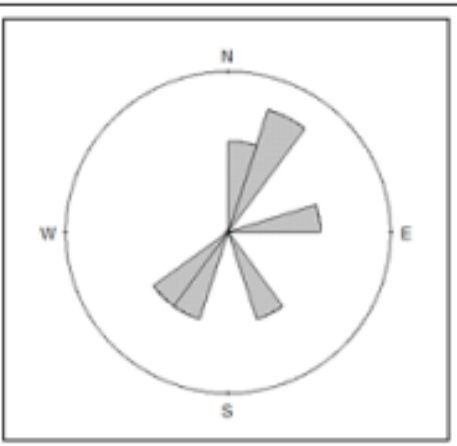

(c)

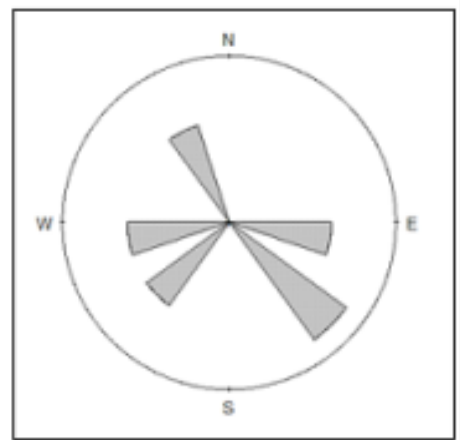

(f)

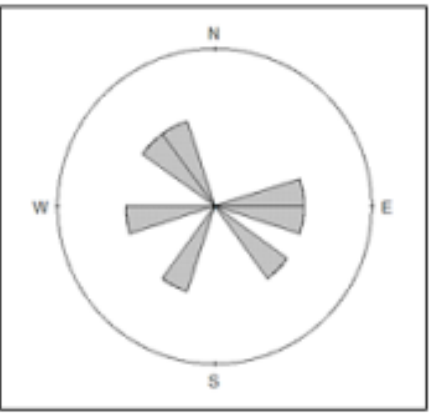

(i)

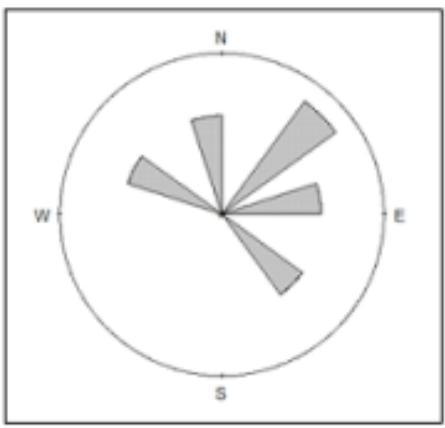

(I)

Figura 6: Variação em relação ao mês anterior na orientação do deslocamento da população de Casiornis rufus (maria-ferrugem) durante o período de 2009 a 2015. a) Janeiro-Dezembro; b) Fevereiro-Janeiro; c) Março-Fevereiro; d) Abril-Maio; e) Maio-Abril; f) Junho-Maio; g) JulhoJunho; h) Agosto-Julho; i) Setembro-Agosto; j) Outubro-Setembro; k) Novembro-Outubro; I) Dezembro-Novembro. 
A espécie Elaenia chiriquensis (chibum) é uma ave migratória na região do Brasil Central (Negret et al, 1984; Marini e Cavalcanti, 1990; Sick, 1997) e apresentou uma grande variação na abundância de indivíduos, nos meses de janeiro a março, durante o verão, houve em torno de 60 indivíduos e foi declinando até o mês de abril, que chega a ter em torno de 20 indivíduos, mantendo a quantidade baixa, em torno de 40 indivíduos, até o mês de julho (Figura 7). A partir de agosto houve um aumento da população, que nos meses de setembro a dezembro, durante a primavera, haviam de 80 a 120 espécies (Figura 7), conforme descrito por Medeiros e Marini (2007), que essa ave é comum no cerrado sensu stricto e cerrado ralo nos meses de agosto a janeiro, quando se reproduz.

Houve variação nos locais de concentração da espécie, sendo encontrado em todos os estados do Brasil, porém em mais quantidade nas regiões Centro-Oeste, Sudeste e Sul e algumas espécies no Peru (Figura 8). A migração latitudinal e longitudinal apresentou deslocamento em todos os sentidos, somente nos meses de janeiro a fevereiro houve deslocamento em direção noroeste (Figura 9, (b)) e nos meses de setembro a outubro, durante a primavera, houve deslocamento somente em direção oeste (Figura 9, (j)).

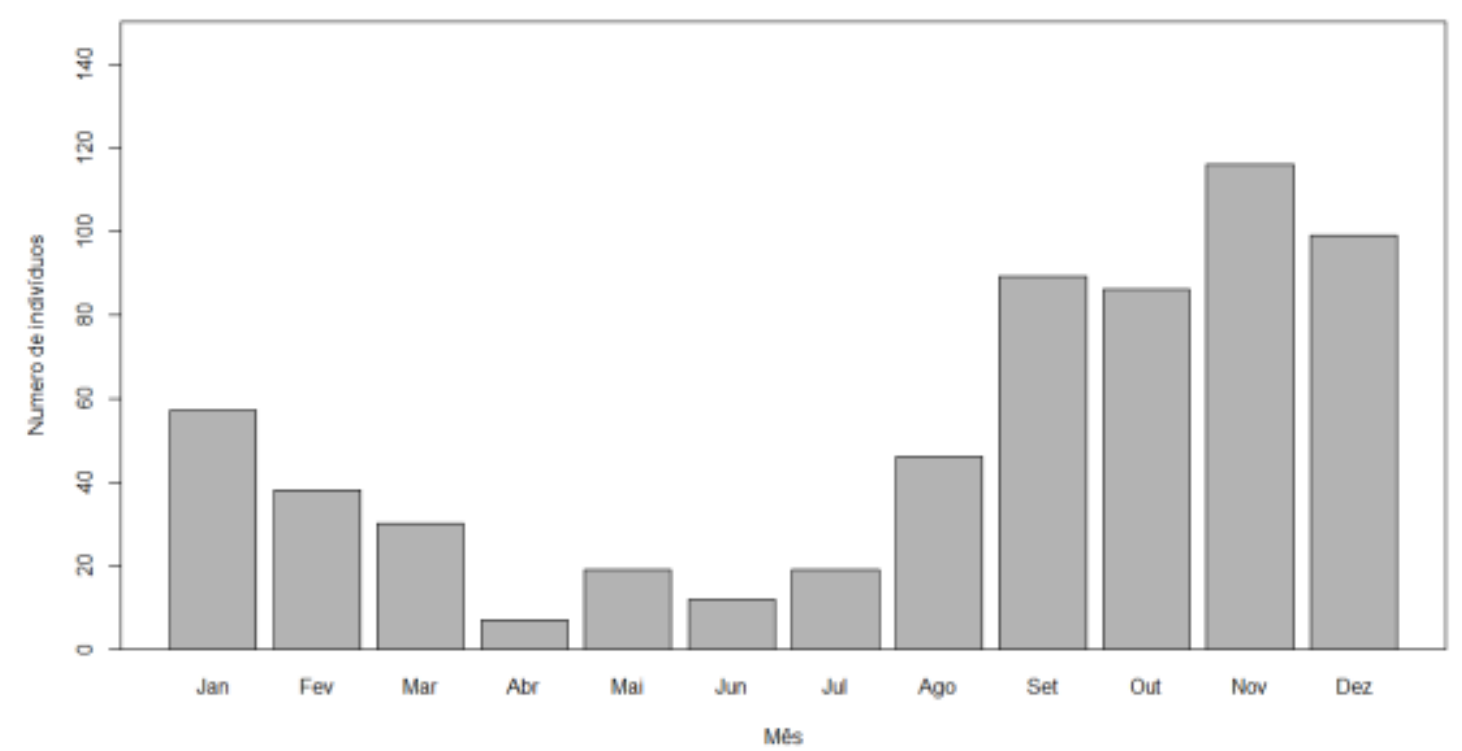

Figura 7: Abundância média mensal da população de chibum (Elaenia chiriquensis) durante o período de 2009 a 2015. 
Segundo Marini e Cavalcanti (1990), existem uma população migratória reproduzindo no centro-sul do Brasil (em Brasília de setembro a dezembro) e invernando no Centro-Oeste e Amazônia (há registros todo ano). A maior parte da população é migratória e ocupa sazonalmente os cerrados (Cavalcanti, 1990; Marini e Cavalcanti, 1990), capturas dessas aves em redes ornitológicas na Estação Ecológica de Águas Recomendadas (DF), ao longo dos meses entre os anos 2002 e 2007 demonstraram que é uma espécie migratória (Miguel Â. Marini com. Pess., 2007). 


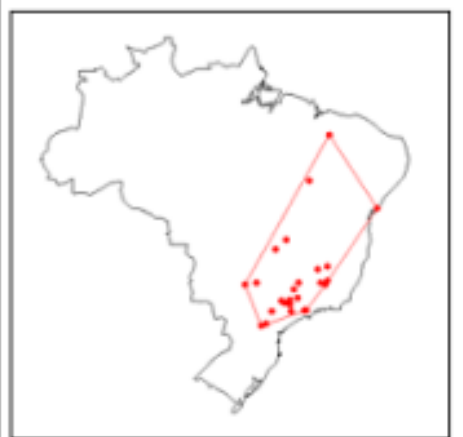

(a)

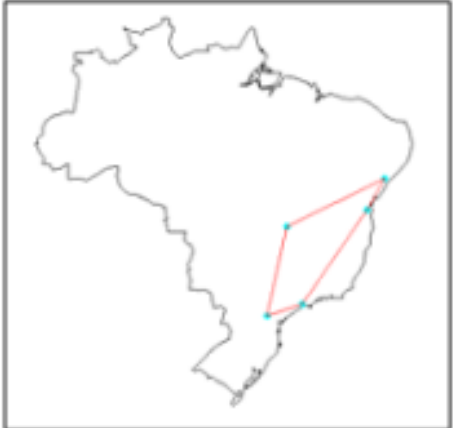

(d)

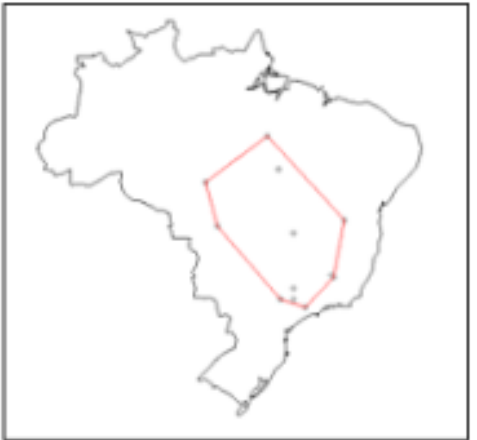

(g)

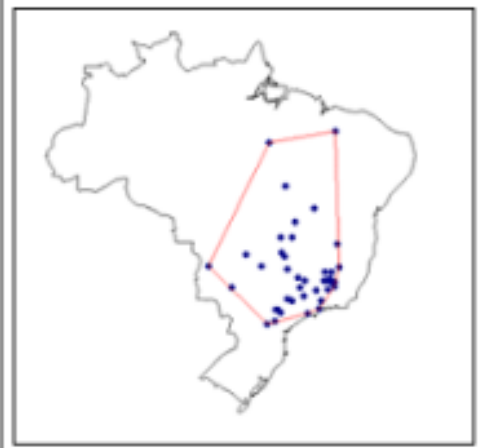

(j)

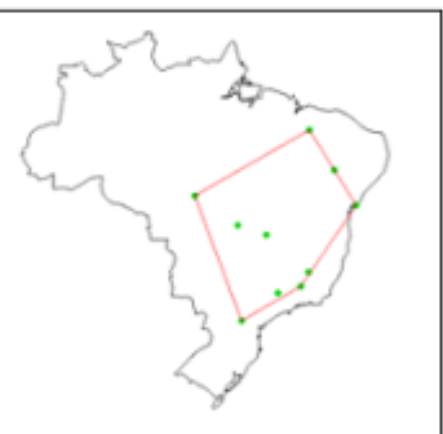

(b)

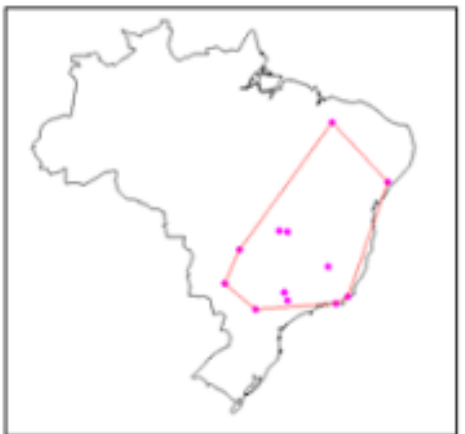

(e)

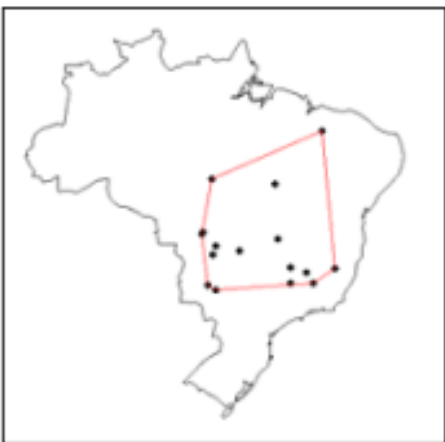

(h)

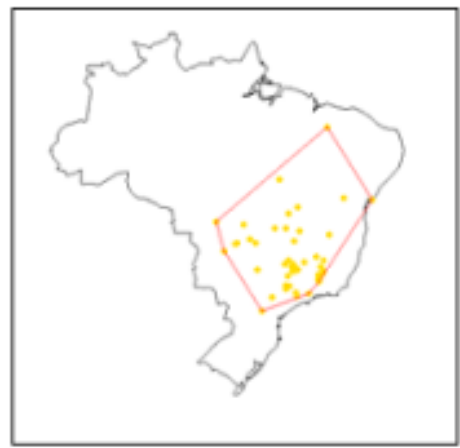

(k)

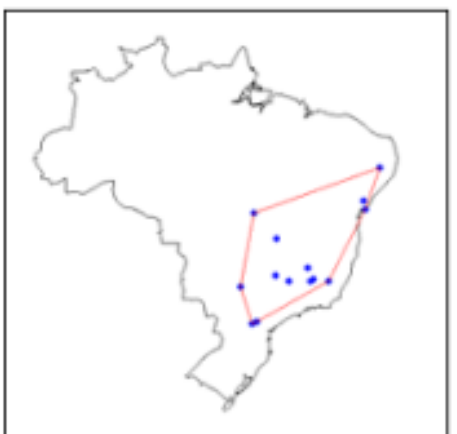

(c)

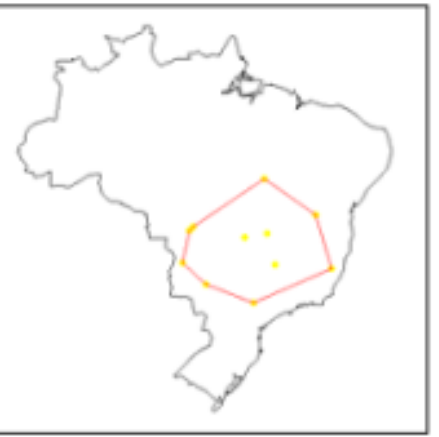

(f)

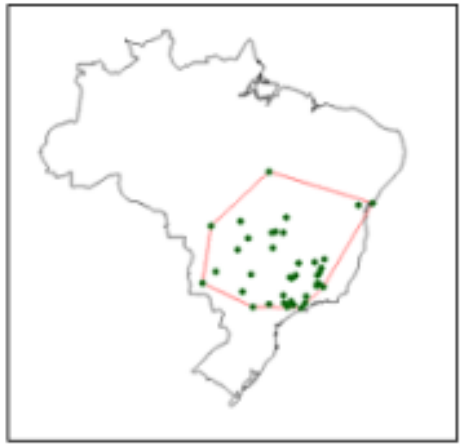

(i)

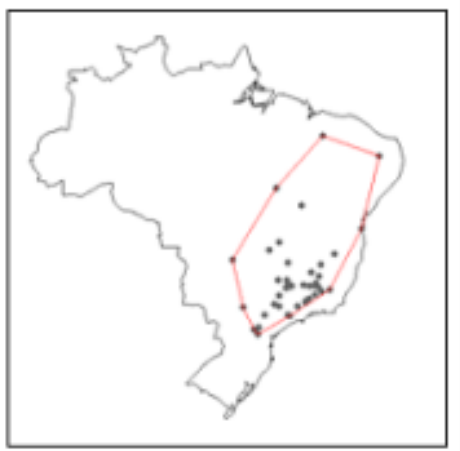

(I)

Figura 8: Concentração média mensal da população de chibum (Elaenia chiriquensis) durante o período de 2009 a 2015. a) Janeiro; b) Fevereiro; c) Março; d) Abril; e) Maio; f) Junho; g) Julho; h) Agosto; i) Setembro; j) Outubro; k) Novembro; I) Dezembro. 


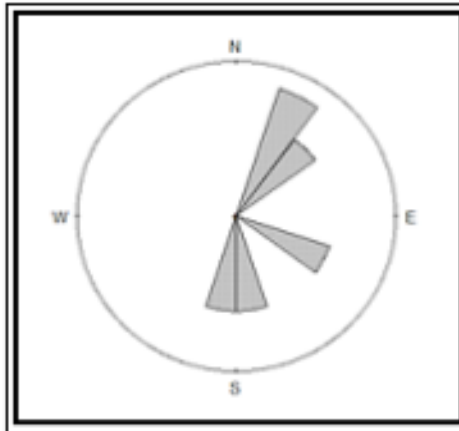

(a)

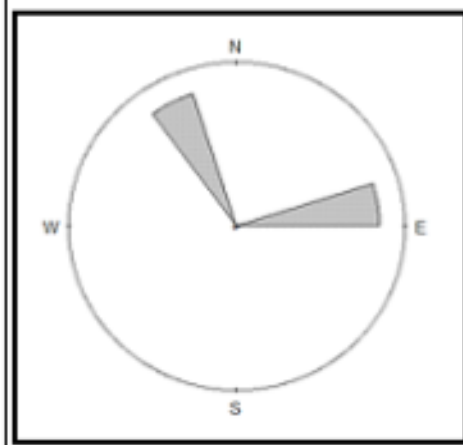

(d)

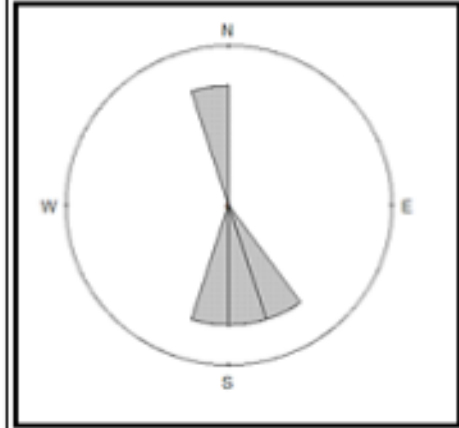

(g)

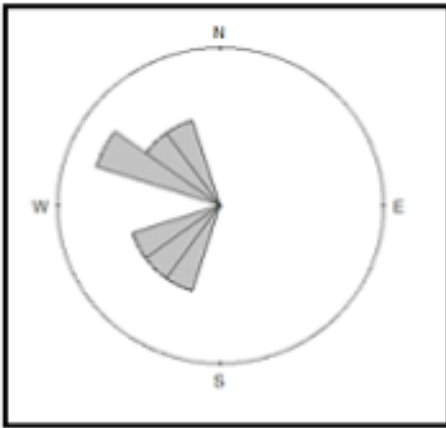

(j)

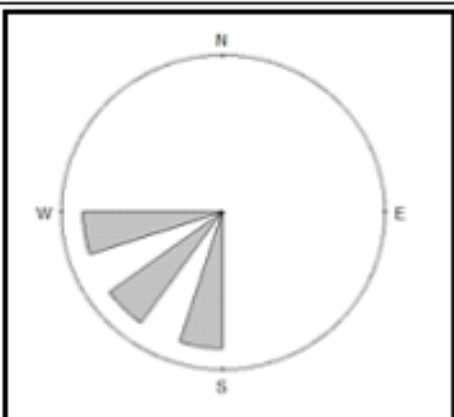

(b)

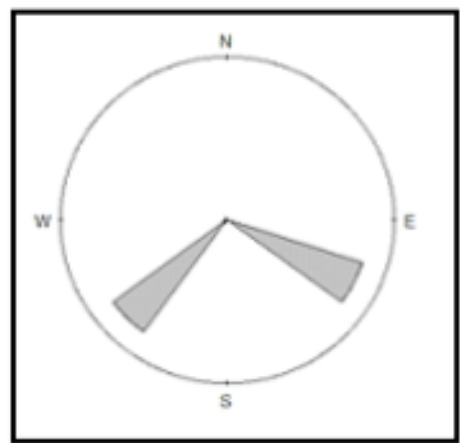

(e)

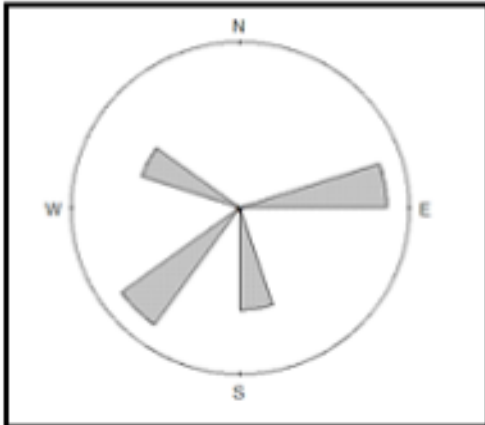

(h)

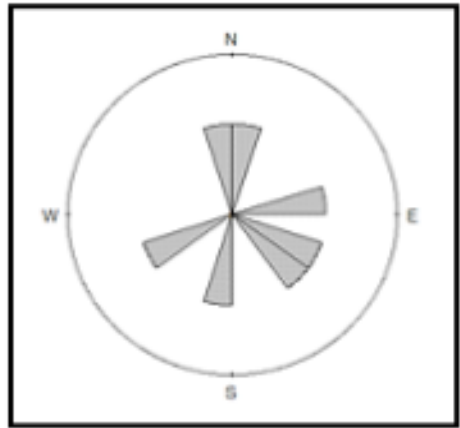

(k)

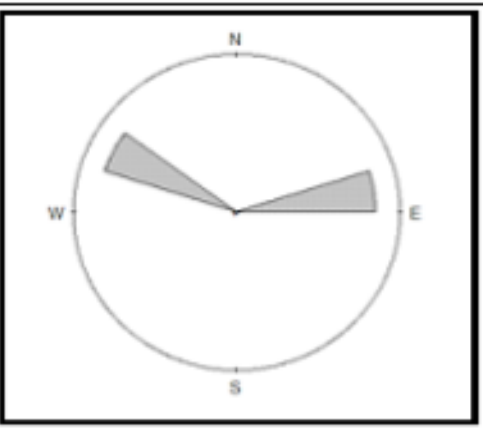

(c)

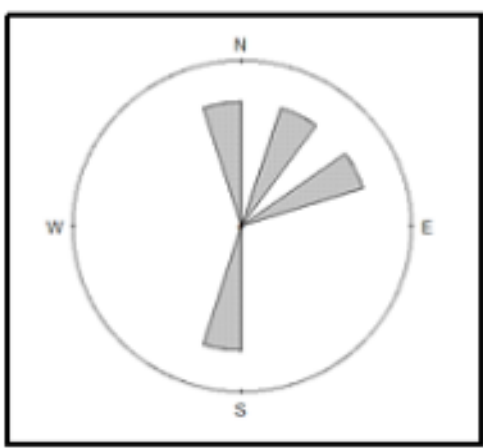

(f)

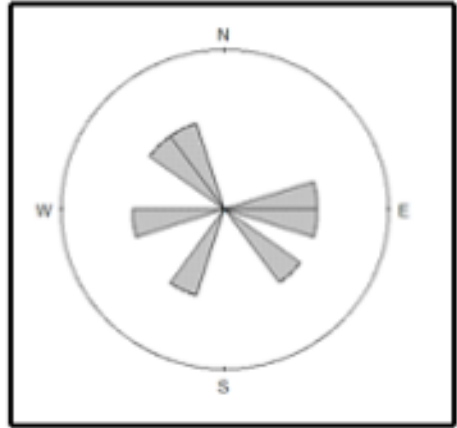

(i)

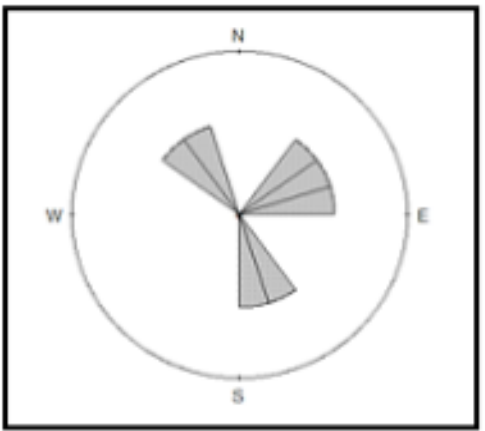

(I)

Figura 9: Variação em relação ao mês anterior na orientação do deslocamento da população de chibum (Elaenia chiriquensis) durante o período de 2009 a 2015. a) Janeiro-Dezembro; b) Fevereiro-Janeiro; c) Março-Fevereiro; d) Abril-Maio; e) Maio-Abril; f) Junho-Maio; g) JulhoJunho; h) Agosto-Julho; i) Setembro-Agosto; j) Outubro-Setembro; k) Novembro-Outubro; I) Dezembro-Novembro. 
A espécie Myiarchus swainsoni (irré) apresentou uma grande variação na abundância de indivíduos nos meses de janeiro a março. Durante o verão foi observado em torno de 50 indivíduos, declinando até o mês de abril, que chega a ter em torno de 20 indivíduos, mantendo a quantidade baixa até o mês de julho, em torno de 40 indivíduos (Figura 10). A partir de setembro, primavera, houve um aumento da população e entre outubro e novembro foram registradas mais de 300 indivíduos (Figura 10). O local de concentração da espécie é nas regiões Centro-Oeste, Sudeste e Sul, além de alguns registros no Peru. Entretanto, houve uma pequena variação nos meses de junho a agosto, estação de inverno, onde a concentração da espécie foi na região Centro-Oeste e Sudeste (Figura 11). A migração latitudinal e longitudinal apresentou deslocamento em todos os sentidos, não havendo uma variação significativa nas estações do ano (Figura 12)

Os resultados indicaram pequenos deslocamentos latitudinais ao longo do ano para todas as espécies investigadas. Adicionalmente, não foi observado uma orientação consistente nos deslocamentos feitos para todas as espécies estudadas. Os resultados parecem sugerir que o processo migratório nas espécies investigadas ocorre em uma escala menor, possivelmente relacionado a variações nas condições ambientais locais.

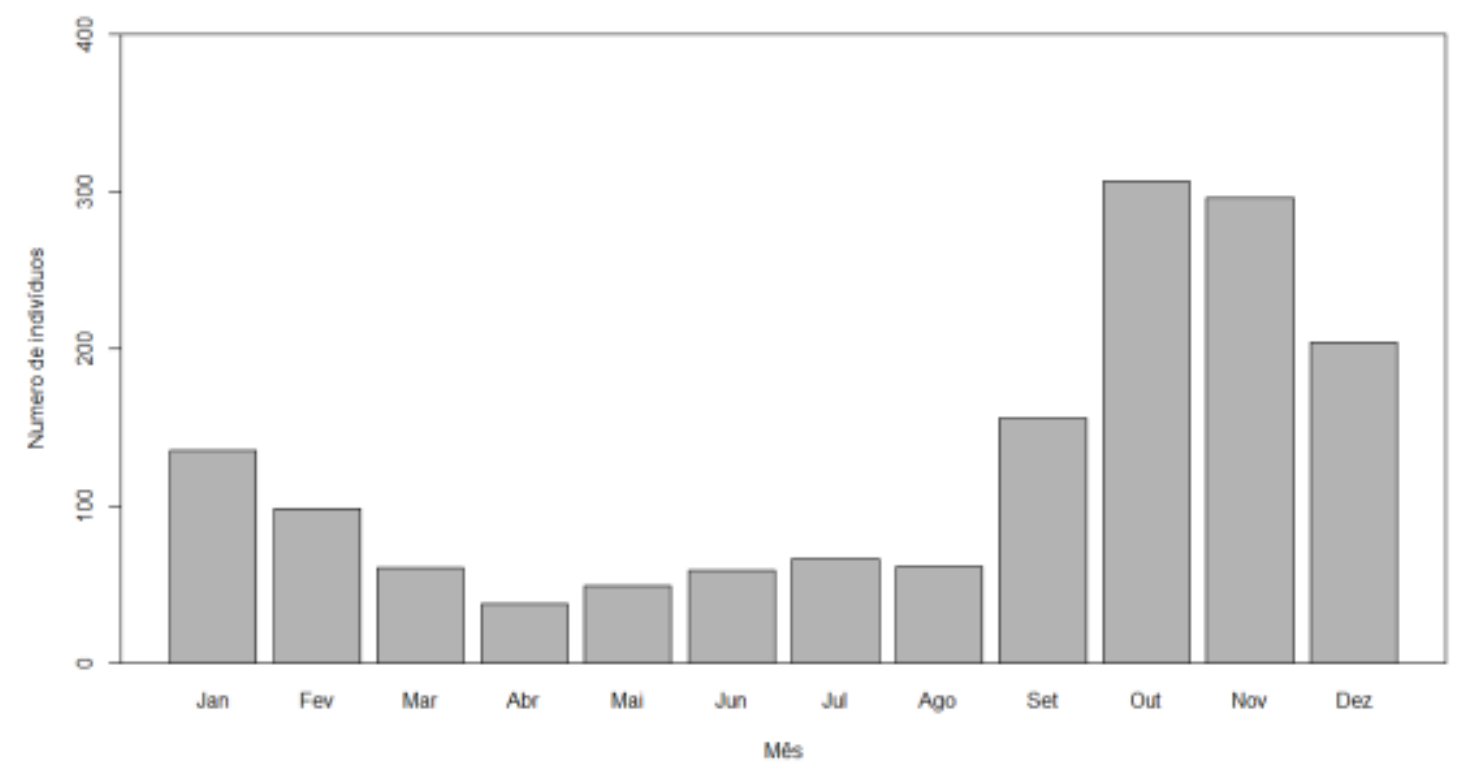

Figura 10: Abundância média mensal da população de irré (Myiarchus swainsoni) durante o período de 2009 a 2015. 


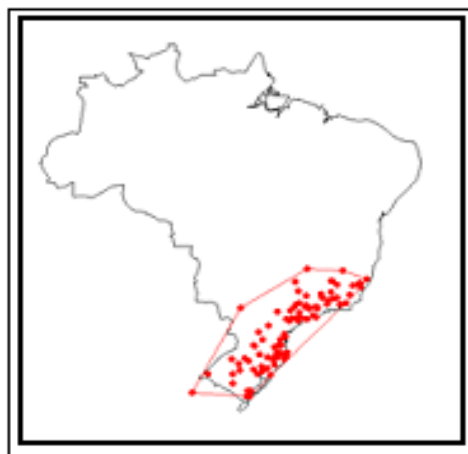

(a)

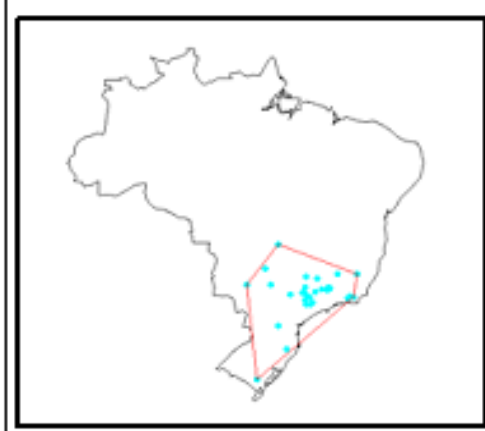

(d)

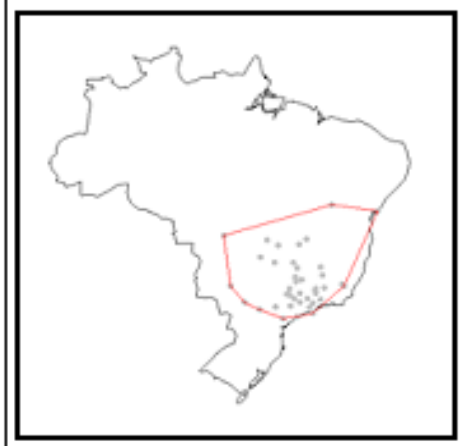

(g)

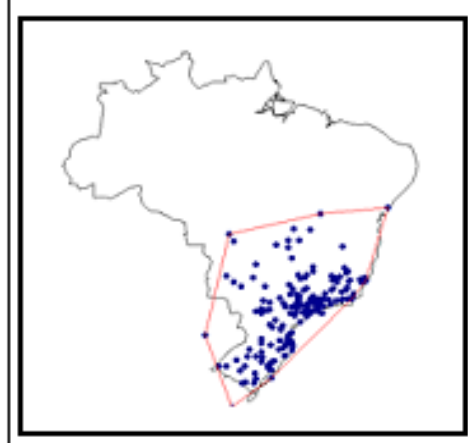

(j)

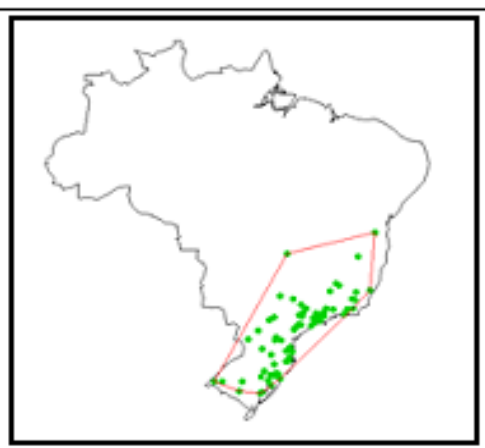

(b)

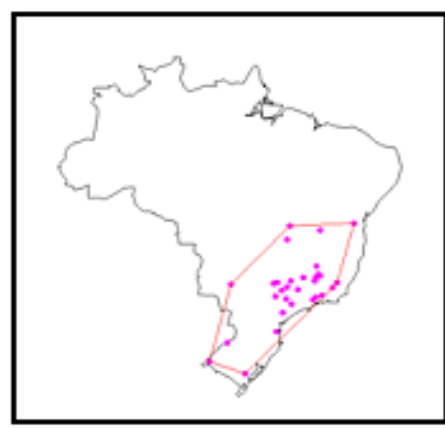

(e)

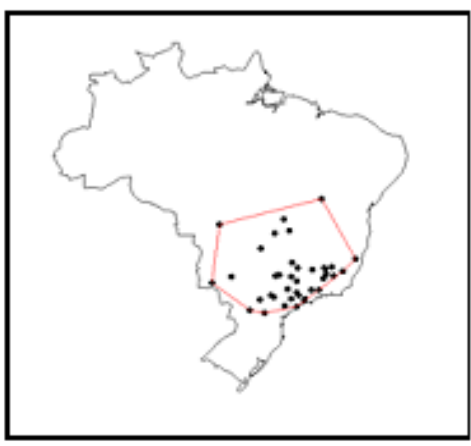

(h)

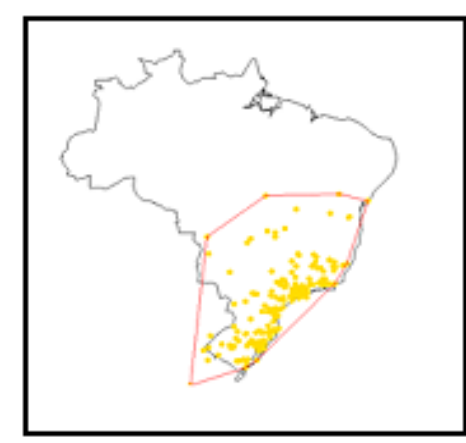

(k)

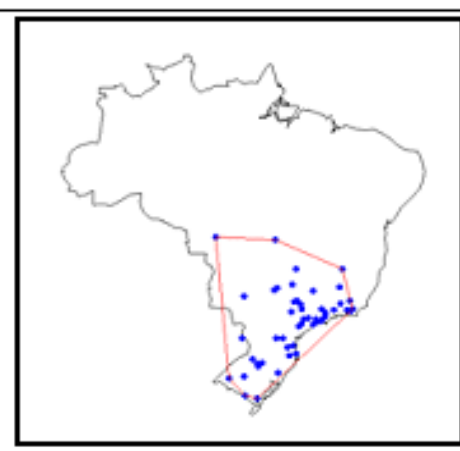

(c)

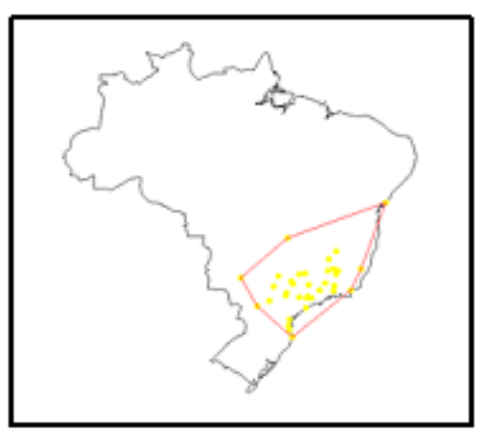

(f)

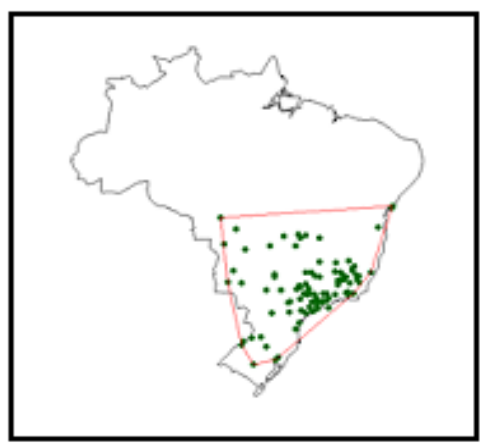

(i)

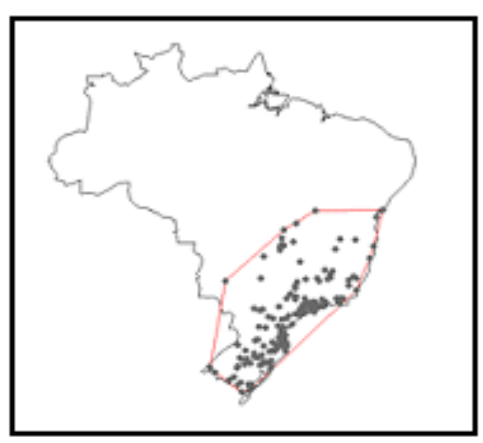

(I)

Figura 11: Variação média mensal da espécie Myiarchus swainsoni (irré). a) Janeiro; b) Fevereiro; c) Março; d) Abril; e) Maio; f) Junho; g) Julho; h) Agosto; i) Setembro; j) Outubro; k) Novembro; I) Dezembro. 


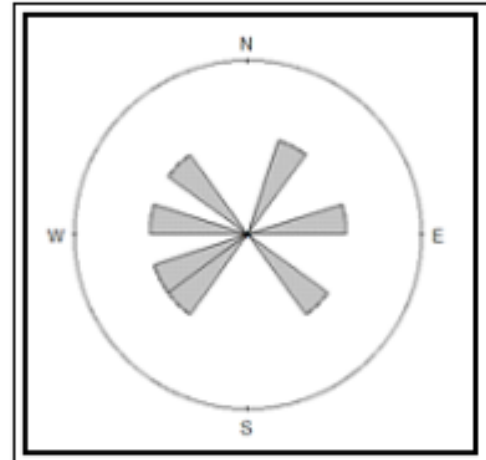

(a)

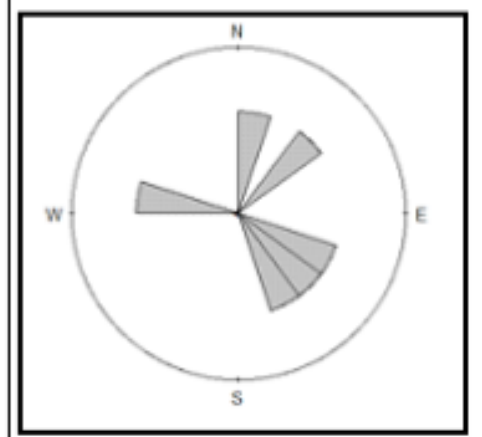

(d)

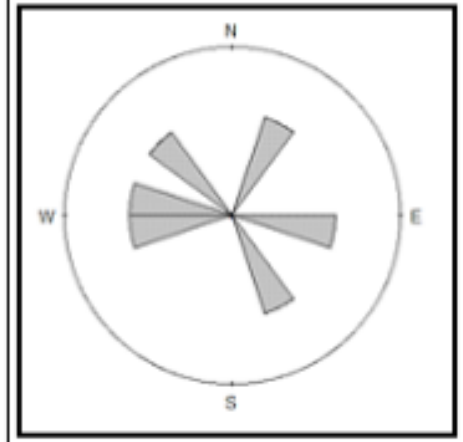

(g)

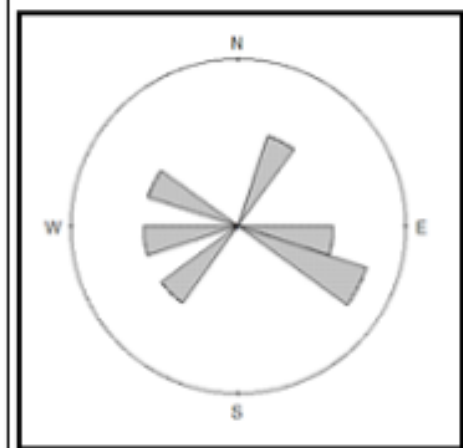

(j)

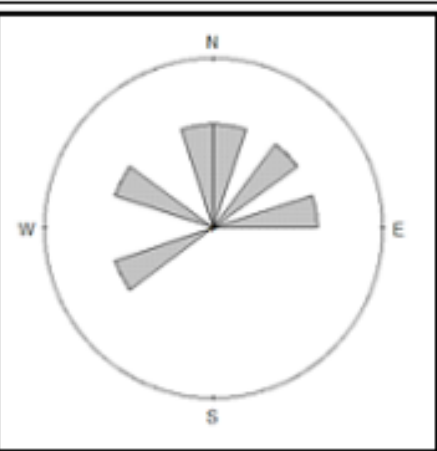

(b)

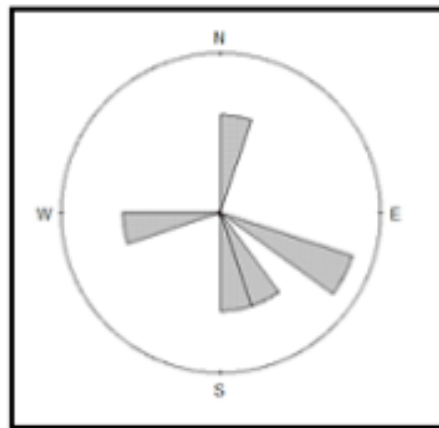

(e)

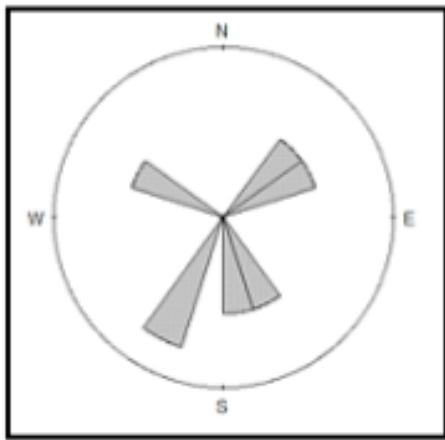

(h)

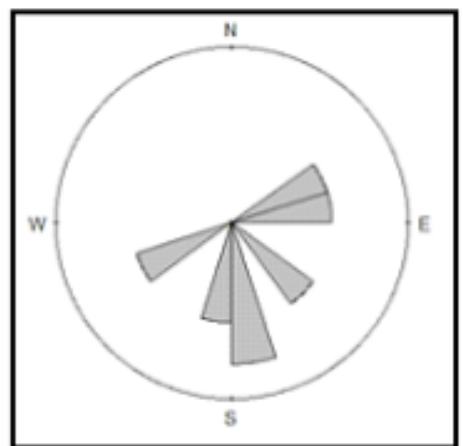

(k)

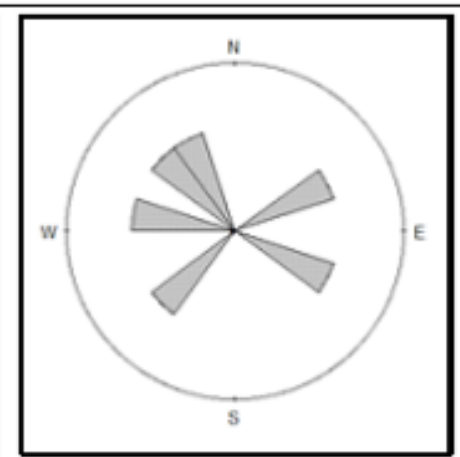

(c)

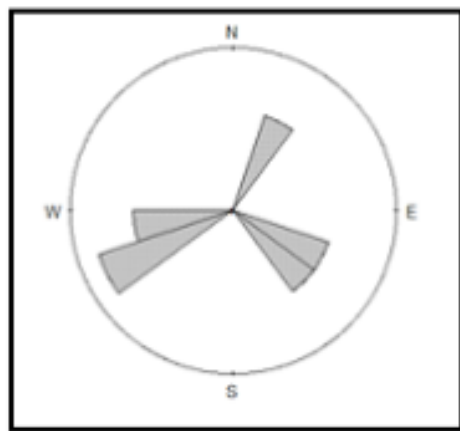

(f)

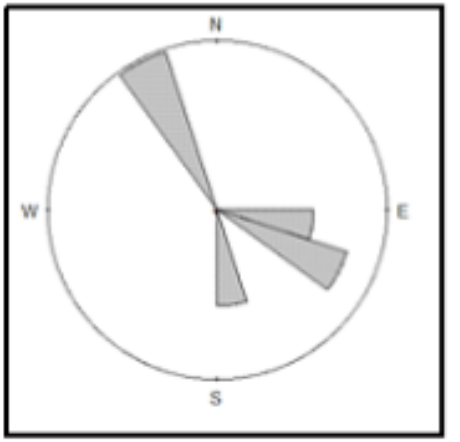

(i)

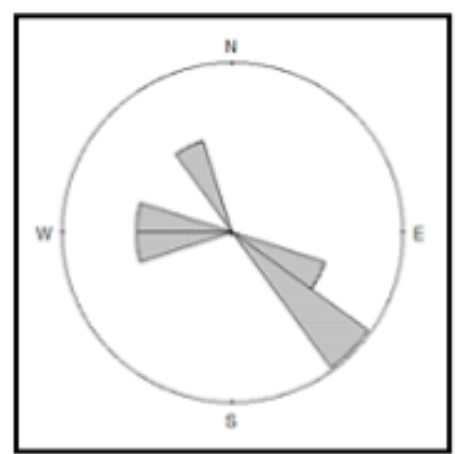

(I)

Figura 12: Variação em relação ao mês anterior na orientação do deslocamento da população da espécie irré (Myiarchus swainsoni). a) Janeiro-Dezembro; b) Fevereiro-Janeiro; c) MarçoFevereiro; d) Abril-Maio; e) Maio-Abril; f) Junho-Maio; g) Julho-Junho; h) Agosto-Julho; i) Setembro-Agosto; j) Outubro-Setembro; k) Novembro-Outubro; I) Dezembro-Novembro. 


\section{Considerações finais}

Os padrões migratórios das espécies Neotropicais aparentam apresentar maior variação e complexidade do que observado nos tradicionais migrantes de altas latitudes. Apesar do registro reduzido para algumas espécies, os dados sugerem a inexistência de rotas migratórias bem definidas para as espécies investigadas. Aparentemente, as espécies Myiarchus swainsoni (suiriricavaleiro) e Elaenia chiriquensis (chibum) apresentam um padrão de migração latitudinal, apesar de não ter sido possível identificar a área final de invernada. Os dados sugerem que a espécie Casiornis rufus (maria-ferrugem) apresenta um padrão de migração longitudinal, com movimentações regionais. Por outro lado, não está claro se a espécie Machertonis rixosa (irré) apresenta movimentos migratórios. Se os mesmos ocorrerem, devem ser influenciados por variações nas condições locais como a disponibilidade de recursos e clima.

$\mathrm{Na}$ Europa e América do Norte pesquisas sobre migrações têm produzido informações por centenas de anos, gerando um bom conhecimento sobre o tema nessas regiões. Na América do Sul faltam informações e as existentes normalmente são apenas em escala local. Segundo Alves (2007), o Brasil, pela sua extensa área e ecossistemas que abriga é o país da América do Sul com maior potencialidade para desvendar as questões relacionadas à migração. Necessitamos obter mais informações sobre a dinâmica migratória e rotas de migrações das aves, de maneira sistematizada e integrá-las em um banco de dados para acesso, principalmente para os pesquisadores. A disponibilidade pública de dados sobre migração de aves é importante para o estudo e conservação de aves migratórias no Brasil. 


\section{Referências Bibliográficas}

Alerstam, S.; HEDENSTRÖM, A. Migration. In: Sutherland, W. \& Newton, I. (EDs). Bird Ecology and Conservation: a handbook of techniques. p. 161-176, 2004.

ALERSTAM, T; HEDENSTRÖM, A. The development of Bird migration theory. Journal of Avian Biology: 29, p. 343-369, 1998.

ALVES, M.A.S. Sistemas de migrações de aves em ambientes terrestres no Brasil: exemplos, lacunas e propostas para o avanço do conhecimento. Revista Brasileira de Ornitologia: 15 (2), p. 231-238, 2007.

AMORIM, D.S.; PIRES, M.R.S. Neotropical biogeography and a method for maximum biodiversity estimation. In: BICUDO, C.E.M.; MENEZES, N.A. Biodiversity in Brazil: a first approach: proceedings. São Paulo: CNPq, 1996.

ANDRADE, M.C. A vida das aves: introdução à biologia e conservação. Fundação Acangaú, Belo Horizonte - Minas Gerais, 1993.

ANTAS, P.T.Z. Migration and other movements among the lower Paraná River valley wetlands, Argentina, and the South Brazil/Pantanal wetlands. Bird Conservation International: 4 (2), p.181-190, 1994.

ARETA, J.I.; BODRATI, A. Un sistema migratorio longitudinal dentro de la selva atlântica: movimientos estacionales y taxonomía del Tangará Cabeza Celeste (Euphonia cyanocephala) em Misiones (Argentina) y Paraguai. Ornitologia Neotropical: 21, p. 71-86, 2010.

BAKER, R.R. Fantastic Journeys: Marvels of Animal Migration, Murdoch Books, 1991.

BERTHOLD, P. Bird Migration A General Survey, Oxford University Press, 253 p., 2001.

BROMMER, J.E. The range margins of northern birds sift polewards. Annales Zoologici Fennici: 41,p. 391-397, 2004.

CABRAL, S.A.S.; AZEVEDO JÚNIOR, S.M.; LARRAZÁBAL, M.E. Abundância sazonal de aves migratórias na Área de Proteção Ambiental de Piaçabuçu, Alagoas, Brasil. Revista Brasileira de Zoologia: 23 (3), p. 865-869, 2006. 
CAMPOS, C.E.C.; NAIFF, R.H.; ARAÚJO, A.S. Censo de aves migratórias (Charadriidae e Scolopacidae) da Porção Norte da Bacia Amazônica, Macapá, Amapá, Brasil. Ornitologia: 3 (1), p. 38-46, 2008.

CHESSER, R.T. Migration in South America: an overview of the austral system. Bird Conservation International: 4, p. 91-107, 1994.

COMITÊ BRASILEIRO DE REGISTROS ORNITOLÓGICOS (CBRO). Lista de aves do Brasil. 11 ${ }^{a}$ Edição, 2014. Disponível em http://www.cbro.org.br. Acesso em: [10/07/2014].

COTTON, P.A Avian migration phenology and global climate change. Proceedings of the National Academy of Sciences of the United States of America: 100, p. 12219-22, 2003.

CRICK, H.Q.P. The impacto of climate change on birds. Ibis: 146, p.48-56, 2004.

CUETO, V.R.; JAHN, A.E. Sobre la necesidad de tener un nombre estandarizado para las aves que migran dentro de América del Sur. Hornero: 23, p. 1-4, 2008.

DUNN, P. Breeding dates and reproductive performance. Advances in Ecological Research: Birds and Climate Change: 35, p. 69-87, 2004.

FIEDLER, W.; BAIRLEIN, F.; KÖPPEN, U. Using large-scale data from ringed birds for the investigation of effects of climate change on migrating birds: pitfalls and prospects. Advances in Ecological Research: Birds and Climate Change: 35, p. 49-67, 2004.

FITZPATRICK, J.W. Foraging behavior of neotropical tyrant flycatchers. Condor: 82, p. 43-57, 1980.

FIZPATRICK, J.W. Family Tyrannidae (Tyrant-flycatchers). Handbook of the birds of the world (ed. By DEL HOYO, J.; ELLIOTT, A; CHRISTIE, D.A.), p. 170462, vol. 9, Cotingas to Pipits and Wagtails. Lynx Edicions, Barcelona, 2004.

GOLDANI, Â; CARVALHO, G.S. Análise de parcimônia de endemismo de cercopídeos neotropicais (Hemiptera, Cercopidae). Revista Brasileira de Entomologia: 47 (3), p. 437-442, 2003. 
HAYES, F.E. Definitions for migrant birds: what is a neotropical migrant? Auk: 112, p. 521-523, 1995.

INSTITUTO CHICO MENDES DE CONSERVAÇÃO DA BIODIVERSIDADE. Relatório anual de rotas e áereas de concentração de aves migratórias no Brasil. Cabedelo, PB: CEMAVE/ ICMBio, 2014.

JOSEPH, L. Towards a broader view of neotropical migrants: consequences of a re-examination of austral migration. Ornitologia Neotropical: 8, p. 31-36, 1997. MARINI, M. Â.; CAVALCANTI, R.B. Migrações de Elaenia albiceps chilensis e Elaenia chiriquensis albivertex (Aves: Tyrannidae). Boletim do Museu Paraense Emílio Goeldi, Série Zoologia: 6, p-59-67, 1990.

MARTIN, T.E. Avian life-history evolution has na eminent past: does it have a bright future? Auk: 121, p. 289-301, 2004.

MEDEIROS, R.C.S.; MARINI, M. Â. Biologia reprodutiva de Elaenia chiriquensis (Lawrence, 1865) (Aves: Tyrannidae) em cerrado do Brasil Central. Revista Brasileira de Zoologia: 24, p. 12-20, 2007.

MILNER-GULLAND, E.J.; FRYXELL, J. M.; SINCLAIR, A. R. E. Animal Migration: A Synthesis. Oxford: Oxford University Press, 2011.

NEGRET, A.J.; NEGRET, R.A. As aves migratórias do Distrito Federal. Boletim Técnico n 6, Brasília, IBDF, 64 p., 1981.

NEGRET, A.; TAYLOR, J.; SOARES, R.B.; CAVALCANTI e C. JOHNSON. Aves da região geopolítica do Distrito Federal. Brasília, SEMA, 21p., 1984.

NEWTON, I. The Migration Ecology of Birds. United Kingdom: Academic Press, 1 ed., 2008.

NIVEN, D.K.; SAUER, J.R.; BUTHER, G.S.; LINK, W.A. Christmas Bird Count Provides Insights Into Population Change in Land Birds That Breed in the Boreal Forest, 2004.

PETERSON, R. T. As aves - $1^{\text {a }}$ edição. Rio de Janeiro: Livraria José Olympio Editora S. A., 1971.

PULIDO, F.; BERTHOLD, P. Current selection for lower migratory activity will drive the evolution of residency in a migratory bird population. Proceedings of 
the National Academy of Sciences of the United States of America: 107, p. 7341-7346, 2010.

RIDGLELY, R.S.; TUDOR, G. The birds of South America volume I, The Oscine Passerines: Jays, Swallows, Wrens, Thrushes and Allies, Vireos, Woodwarblers, Tanagers, Icterids and Finches. The University of Texas, Austin, 1989.

RIDGELY, R.S.; TUDOR, G. The birds of South America volume II, The Suboscine Passerines: Ovenbirds and Woodcreepers, Antbirds, Gnateaters, and Tapaculos, Tyrant Flycatchers, Manakins and Cotingas. The University of Texas, Austinm 1994.

SICK, H. Order Strigiformes. In: Ibird. (Eds.), Birds in Brazil: a natural history. Princeton University Press, Princeton, Usa, p. 286-298, 1993.

SICK, H. Ornitologia Brasileira. Rio de Janeiro: Nova fronteira, 1997.

TELINO JR, W.R.; AZEVEDO JR., S.M.; LYRA-NEVES, R.M. Censo de aves migratórias (Charadriidae, Scolopacidae e Laridae na Coroa do Avião, Igarassu, Parnambuco, Brazil). Revista Brasileira de Zoologia: 20 (3), p. 451 456, 2003. 


\section{APÊNDICE}

Machertonis rixosa (suiriri-cavaleiro)

WikiAves

\begin{tabular}{lccccc}
\hline Mês & $\begin{array}{l}\text { Cuidando/ } \\
\text { alimentando } \\
\text { filhotes(s) }\end{array}$ & $\begin{array}{l}\text { Presença } \\
\text { de } \\
\text { filhote(s) }\end{array}$ & $\begin{array}{l}\text { Presença } \\
\text { de ninho }\end{array}$ & $\begin{array}{l}\text { Construindo } \\
\text { ninho }\end{array}$ & $\begin{array}{l}\text { Alimentando- } \\
\text { se/caçando }\end{array}$ \\
\hline Jan & 8 & 1 & 4 & 1 & 83 \\
Fev & 9 & 1 & 2 & 1 & 55 \\
Mar & 1 & 1 & 1 & 0 & 54 \\
Abr & 1 & 0 & 1 & 0 & 40 \\
Mai & 2 & 0 & 0 & 0 & 60 \\
Jun & 2 & 0 & 2 & 0 & 61 \\
Jul & 1 & 0 & 1 & 1 & 79 \\
Ago & 0 & 0 & 2 & 1 & 68 \\
Set & 2 & 0 & 0 & 1 & 48 \\
Out & 4 & 2 & 6 & 4 & 59 \\
Nov & 5 & 4 & 6 & 4 & 67 \\
Dez & 9 & 4 & 3 & 2 & 62 \\
\hline
\end{tabular}

\section{Países:}

(Wiki Aves e Xeno-Canto)

Argentina (2009, 2010, 2011, 2012, 2013, 2014, 2015, 2016)

Uruguai $(2009,2012,2013,2014,2015)$

Guatemala (2015)

Paraguai (2013)

Venezuela $(2010,2013)$

Colômbia $(2011,2015)$

Panamá (2015) 
Casiornis rufus (maria-ferrugem)

WikiAves

\begin{tabular}{lccccc}
\hline Mês & $\begin{array}{l}\text { Cuidando/ } \\
\text { alimentando } \\
\text { filhotes(s) }\end{array}$ & $\begin{array}{l}\text { Presença } \\
\text { de } \\
\text { filhote(s) }\end{array}$ & $\begin{array}{l}\text { Presença } \\
\text { de ninho }\end{array}$ & $\begin{array}{l}\text { Construindo } \\
\text { ninho }\end{array}$ & $\begin{array}{l}\text { Alimentando- } \\
\text { se/caçando }\end{array}$ \\
\hline Jan & 0 & 0 & 0 & 0 & 0 \\
Fev & 0 & 0 & 0 & 0 & 2 \\
Mar & 0 & 0 & 0 & 0 & 0 \\
Abr & 0 & 0 & 0 & 0 & 0 \\
Mai & 0 & 0 & 0 & 0 & 0 \\
Jun & 0 & 0 & 0 & 0 & 1 \\
Jul & 0 & 0 & 0 & 0 & 0 \\
Ago & 0 & 0 & 0 & 0 & 0 \\
Set & 0 & 9 & 0 & 1 & 1 \\
Out & 2 & 0 & 0 & 0 & 1 \\
Nov & 0 & 0 & 0 & 0 & 0 \\
Dez & 0 & 0 & 0 & 0 & 1 \\
\hline
\end{tabular}

Países:

(Wiki Aves e Xeno-Canto)

Peru $(2010,2013,2011)$ 
Elaenia chiriquensis (chibum)

WikiAves

\begin{tabular}{lccccc}
\hline Mês & $\begin{array}{l}\text { Cuidando/ } \\
\text { alimentando } \\
\text { filhotes(s) }\end{array}$ & $\begin{array}{l}\text { Presença } \\
\text { de } \\
\text { filhote(s) }\end{array}$ & $\begin{array}{l}\text { Presença } \\
\text { de ninho }\end{array}$ & $\begin{array}{l}\text { Construindo } \\
\text { ninho }\end{array}$ & $\begin{array}{l}\text { Alimentando- } \\
\text { se/caçando }\end{array}$ \\
\hline Jan & 1 & 0 & 0 & 0 & 2 \\
Fev & 0 & 0 & 0 & 0 & 1 \\
Mar & 0 & 0 & 0 & 0 & 0 \\
Abr & 0 & 0 & 0 & 0 & 0 \\
Mai & 0 & 0 & 0 & 0 & 0 \\
Jun & 0 & 0 & 0 & 0 & 0 \\
Jul & 0 & 0 & 0 & 0 & 1 \\
Ago & 0 & 0 & 1 & 1 & 0 \\
Set & 0 & 2 & 2 & 2 & 1 \\
Out & 2 & 1 & 4 & 1 & 4 \\
Nov & 1 & 1 & 0 & 0 & 0 \\
Dez & 0 & 1 & 1 & 0 & 2 \\
\hline
\end{tabular}

Países:

(Wiki Aves e Xeno-Canto)

Venezuela (2014)

Panamá (2015)

Equador (2014, 2011, 2012, 2014)

Guiana Francesa $(2010,2011)$

Peru (2009)

Costa Rica (2010) 


\section{Myiarchus swainsoni (Irré)}

WikiAves

\begin{tabular}{lccccc}
\hline Mês & $\begin{array}{l}\text { Cuidando/ } \\
\text { alimentando } \\
\text { filhotes(s) }\end{array}$ & $\begin{array}{l}\text { Presença } \\
\text { de } \\
\text { filhote(s) }\end{array}$ & $\begin{array}{l}\text { Presença } \\
\text { de ninho }\end{array}$ & $\begin{array}{l}\text { Construindo } \\
\text { ninho }\end{array}$ & $\begin{array}{l}\text { Alimentando- } \\
\text { se/caçando }\end{array}$ \\
\hline Jan & 0 & 1 & 0 & 0 & 4 \\
Fev & 0 & 0 & 1 & 0 & 1 \\
Mar & 0 & 0 & 0 & 0 & 1 \\
Abr & 0 & 0 & 0 & 0 & 1 \\
Mai & 0 & 0 & 0 & 0 & 1 \\
Jun & 0 & 0 & 0 & 0 & 1 \\
Jul & 0 & 0 & 0 & 0 & 1 \\
Ago & 0 & 0 & 0 & 0 & 4 \\
Set & 0 & 0 & 0 & 0 & 5 \\
Out & 3 & 0 & 0 & 6 & 6 \\
Nov & 5 & 0 & 0 & 1 & 14 \\
Dez & 1 & 0 & 0 & 1 & 10 \\
\hline
\end{tabular}

\section{Países:}

(Wiki Aves e Xeno-Canto)

Uruguai (2010)

Equador $(2015,2013,2010,2012)$

Venezuela $(2009,2010)$

Colômbia (2011)

Argentina $(2013,2011,2012)$

Bolívia (2012) 